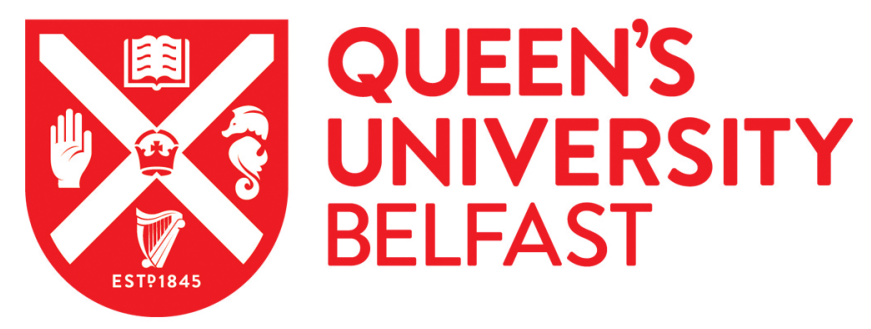

\title{
Compressive intralaminar fracture toughness and residual strength of 2D woven carbon fibre reinforced composites: New developments on
} using the size effect method

Dalli, D., Catalanotti, G., Varandas, L., \& Falzon, B. (2020). Compressive intralaminar fracture toughness and residual strength of $2 \mathrm{D}$ woven carbon fibre reinforced composites: New developments on using the size effect method. Theoretical and Applied Fracture Mechanics, 106, [102487].

https://doi.org/10.1016/j.tafmec.2020.102487

\section{Published in:}

Theoretical and Applied Fracture Mechanics

\section{Document Version:}

Peer reviewed version

Queen's University Belfast - Research Portal:

Link to publication record in Queen's University Belfast Research Portal

\author{
Publisher rights \\ Copyright 2020 Elsevier. \\ This manuscript is distributed under a Creative Commons Attribution-NonCommercial-NoDerivs License \\ (https://creativecommons.org/licenses/by-nc-nd/4.0/), which permits distribution and reproduction for non-commercial purposes, provided the \\ author and source are cited.

\section{General rights} \\ Copyright for the publications made accessible via the Queen's University Belfast Research Portal is retained by the author(s) and / or other \\ copyright owners and it is a condition of accessing these publications that users recognise and abide by the legal requirements associated \\ with these rights.
}

\section{Take down policy}

The Research Portal is Queen's institutional repository that provides access to Queen's research output. Every effort has been made to ensure that content in the Research Portal does not infringe any person's rights, or applicable UK laws. If you discover content in the Research Portal that you believe breaches copyright or violates any law, please contact openaccess@qub.ac.uk. 


\title{
Compressive intralaminar fracture toughness and residual strength of 2D Woven carbon fibre reinforced composites: New developments on using the size effect method
}

\author{
D. Dalli ${ }^{1}$, G. Catalanotti ${ }^{1 *}$, L. F. Varandas ${ }^{1}$, B. G. Falzon ${ }^{1 *}$, S. Foster ${ }^{2}$ \\ ${ }^{1}$ Advanced Composites Research Group (ACRG), School of Mechanical and Aerospace Engineering, Queen's \\ University Belfast, Ashby Building, Stranmillis Road, Belfast BT9 5AH, UK. \\ ${ }^{2}$ McLaren Racing Limited, McLaren Technology Centre, Chertsey Road, Woking, Surrey, GU21 4YH, UK.
}

\begin{abstract}
This paper presents new developments in the use of the size effect method for obtaining the compressive fracture toughness of 2D woven carbon fibre composites. A modification of the Double Edge Notch Compression (DENC) specimen geometry is proposed, to fit the Combined Loading Compression (CLC) standard fixture, and shown to reduce peak load dispersion. The notch tip diameter sensitivity on the peak load is also investigated, experimentally and numerically, and shown not to have a significant influence on fracture toughness. The use of the CLC fixture also allows for the residual compressive strength of the material to be calculated from post-peak crushing.
\end{abstract}

Keywords: Compressive intralaminar fracture toughness, (A) Carbon fibre, (C) Analytical modelling, (C) Computational modelling, (D) Mechanical testing

\footnotetext{
* Corresponding authors.

E-mail address: G.Catalanotti@qub.ac.uk (G.Catalanotti), B.Falzon@qub.ac.uk (B.G.Falzon).
} 


\section{Nomenclature}

$c_{f}$

CV\%

$\operatorname{det} \boldsymbol{F}$

$d_{0}$

$d_{11 T(C)}^{T}$

$d^{m}$

$\delta, \delta_{f}$

$E_{11 C}, E_{22 C}$

$E_{11}^{T}, E_{22}^{T}$

$E_{33}^{T}$

$E_{11 C}^{*}$

$E^{m}$

É

$G_{12}$

$G_{12}^{T}$

$G_{C}, G_{C c}$

$G_{C C}^{1 T}, G_{I C}^{1 T}$

$G_{C C}^{2 T}, G_{I C}^{2 T}$

$G_{I I C}^{12 T}, G_{I I C}^{13 T}, G_{I I C}^{23 T}$

$G_{I c}^{m}$

l

$L_{E C}$

$M, N$

P

R

$R_{S S}$

$S_{12}^{T}, S_{13}^{T}, S_{23}^{T}$

SD

$t$

$\operatorname{tr}(Q)$

$u_{y}, u_{y}$

$u_{z}$

$v_{12}, v_{21}$ critical crack extension for a fully developed fracture process zone

Coefficient of Variation percentage

determinant of the deformation gradient

initial notch tip diameter

longitudinal tensile / compressive damage variable for the tows

matrix damage variable

displacement and the corresponding failure value

in-plane compressive elastic moduli of the weave

in-plane elastic moduli of the tows: longitudinal and transverse

through-thickness elastic modulus of the tows

normalised compressive elastic modulus, with respect to the equivalent modulus

elastic modulus of the epoxy matrix

equivalent modulus

in-plane shear modulus of the weave

in-plane shear modulus of the tows

compressive driving force curve, and its critical value (equal to the fracture toughness)

compressive and tensile longitudinal mode I intralaminar fracture toughness of the fibre tows compressive and tensile transverse mode I intralaminar fracture toughness of the fibre tows in-plane and through thickness mode II intralaminar fracture toughness of the fibre tows mode I fracture toughness of the epoxy matrix

half the specimen length

length of the Embedded Cell

fitting parameters for bilogarithmic regression

compressive load

crack growth resistance

steady-state fracture toughness

in-plane and through-thickness shear strengths of the tows

Standard Deviation

specimen thickness

trace of the stiffness matrix

vertical nodal displacement and velocity

out-of-plane displacement

in-plane major and minor Poisson's ratio of the weave 


\begin{tabular}{|c|c|}
\hline$v_{12}^{T}$ & in-plane Poisson's ratios of the tows \\
\hline$v_{13}, v_{23}$ & through-thickness Poisson's ratios of the weave \\
\hline$v_{13}^{T}, v_{23}^{T}$ & through-thickness Poisson's ratios of the tows \\
\hline$v^{m}$ & Poisson's ratio of the epoxy matrix \\
\hline$V, V_{0}$ & deformed and undeformed volumes of the element \\
\hline$w$ & characteristic specimen size \\
\hline$W_{\text {tow }}$ & width of the finite element model tows \\
\hline$W_{E C}$ & width of the embedded cell \\
\hline$x_{1}, x_{2}$ & in-plane tow axes of the weave: warp, and weft directions \\
\hline$X_{C}^{T}, X_{T}^{T}$ & compressive and tensile longitudinal strengths of the tows \\
\hline$X_{C}^{m}, X_{T}^{m}$ & compressive and tensile strengths of the epoxy matrix \\
\hline$X_{C r}$ & residual compressive strength \\
\hline$Y_{C}^{T}, Y_{T}^{T}$ & compressive and tensile transverse strengths of the tows \\
\hline$\Delta a$ & crack length increment \\
\hline$\alpha, \alpha_{0}$ & shape parameter, and its initial value \\
\hline$\kappa$ & correction factor \\
\hline$\kappa_{0}, \dot{\kappa}_{0}$ & correction factor value at $\alpha=\alpha_{0}$, and its derivative with respect to $\alpha$ \\
\hline$\lambda$ & dimensionless elastic parameter for material orthotropy \\
\hline$\rho$ & dimensionless elastic parameter for material orthotropy \\
\hline$\sigma$ & nominal stress \\
\hline$\sigma_{u}$ & peak nominal stress \\
\hline$\xi$ & shape parameter \\
\hline
\end{tabular}




\section{Introduction}

State-of-the-art physically-based composite damage models require the use of various strength and fracture toughness values in order to properly define the softening laws associated with different failure mechanisms [17]. The experimental procedures used to measure strength and interlaminar fracture toughness have been extensively investigated and standardised (eg. [8-13]). Considering intralaminar fracture toughness, extensive literature can be found on the development of mode I tensile intralaminar fracture toughness experiments ([1417], among others). However, its compressive counterpart is not as well documented. In compression, the initiation and propagation of a crack in a notched structure manifests as a through-thickness kink-band [18,19]. This phenomenon only holds true for notched structures, since unnotched geometries can fail due to other compressive failure mechanisms. Obtaining a correct measurement of the compressive fracture toughness is especially important when modelling impact and crush loading scenarios.

Similar to the tensile experiments, both stable and unstable crack propagation techniques have been proposed to measure this compressive fracture toughness [19-21]. The stable crack propagation techniques have focused on the development of the Compact Compression (CC) specimen geometry combined with different data reduction methods, such as the area method and the Finite Element Method (FEM)-based approach [21]. The FEM approach was proven inaccurate by Catalanotti et al. [22], due to the contact tractions that develop on the crushing faces of the propagated crack. These tractions directly increase the measured load, and also modify the stress distribution around the propagating crack, dissipating energy which does not contribute to the continued kink-band crack propagation, thus leading to an overestimation of the fracture toughness. Furthermore, both of these data reduction techniques require the tracking of the crack length during the stable propagation. While the crack tip is already difficult to locate in stable mode I tensile fracture toughness tests [17], its location becomes even more of a subjective estimate in CC testing, especially when measured optically [22]. Although other less subjective crack measurement techniques have been employed in literature, including Digital Image Correlation (DIC) [22], and infrared thermography [23], such methods might be too complex for industry to adopt.

Unstable crack propagation techniques have been developed based on the size effect method, making use of the energetic (non-statistical) size effect observed in notched composite specimens $[19,20]$. Such methods require experimental testing of scaled notched specimens, from which a size-independent fracture toughness can be calculated [24]. The size effect method, originally developed for concrete [25], and later adapted for the similarly-quasibrittle composite materials [26], has been used to obtain the intralaminar mode I [15,27], mode II [28], and compressive fracture toughness [19,20] of carbon fibre reinforced polymers (CFRP). This technique does not require the measurement of the crack length, but only the peak loads of the scaled specimens. Furthermore, since the peak load in unstable tests occurs just after initial crack propagation, diffused damage only develops after the peak instability, thus not affecting the measured fracture toughness. 
While this size effect method has already been tested on unidirectional (UD) CFRP, no literature is available on bi-dimensional (2D) woven composites in compression. This work seeks to apply the size effect method to derive the compressive crack resistance curve ( $R$-curve) and steady-state fracture toughness $\left(R_{S S}\right)$ of a 5-Harness Satin (5HS) 2D woven CFRP composite. Geometrically-scaled Double Edge Notch Compression (DENC) specimens are tested, from which a size effect law is derived. A significant scatter was observed in the peak nominal stress for UD composite DENC specimens loaded under edge compression [19]. This scatter issue is addressed through a modification of the DENC specimen geometry, to allow the use of a Combined Loading Compression (CLC) fixture [9]. The notch tip diameter sensitivity of the peak load is also investigated for this modified specimen geometry, both experimentally and numerically. The use of the CLC fixture also allows the extraction of post-peak residual crush load data, by maintaining the alignment of the two portions of the fractured specimens after the unstable failure. This crush data is used to calculate the residual compressive strength, $X_{C r}$, along the two fibre-dominated principal directions of the weave, which is another material input property of some current composite damage models [3]. This residual compressive strength is usually estimated to be the transverse matrix-dominated strength in UD composites [29]. However, no literature is available on the residual strength of 2D woven composites, and no standard experiments are available to measure this property. Thus, this work seeks to provide an experimental technique which can provide both the intralaminar compressive fracture toughness and the residual compressive strength of woven CFRP composites.

\section{Data reduction}

\subsection{Size effect method for compressive intralaminar fracture toughness}

Two specimen geometries were investigated (shown in Figure 1), and are hereon referred to as Double Edge Notch Compression (DENC) and Double Edge Notch Combined Loading Compression (DENCLC). The DENC specimens were edge-loaded, similar to the experiments in literature [19]. DENCLC specimens included an additional fixed grip length on each side of the gauge section, to facilitate their use in a standard CLC fixture. An analytical model was used to calculate the compressive fracture toughness from these specimen geometries. Considering a nominal specimen geometry under compressive loading (Figure 2), the compressive energy release rate, $G_{C}$, for a crack propagating perpendicular to the warp direction, $x_{1}$, in a $2 \mathrm{D}$ orthotropic laminate is [30]:

$$
G_{C}=\frac{1}{E} K_{C}^{2}
$$

where $K_{C}$ is the compressive stress intensity factor. Under a state of plane stress, the equivalent modulus, $E$, is calculated as $[15,30]$ :

$$
\begin{gathered}
E=\lambda^{1 / 4} \sqrt{E_{11 C} E_{22 C}\left(\frac{2}{1+\rho}\right)}, \text { where } \\
\lambda=\frac{E_{22 C}}{E_{11 C}}, \quad \rho=\frac{\sqrt{E_{11 C} E_{22 C}}}{2 G_{12}}-\sqrt{v_{12} v_{21}} .
\end{gathered}
$$




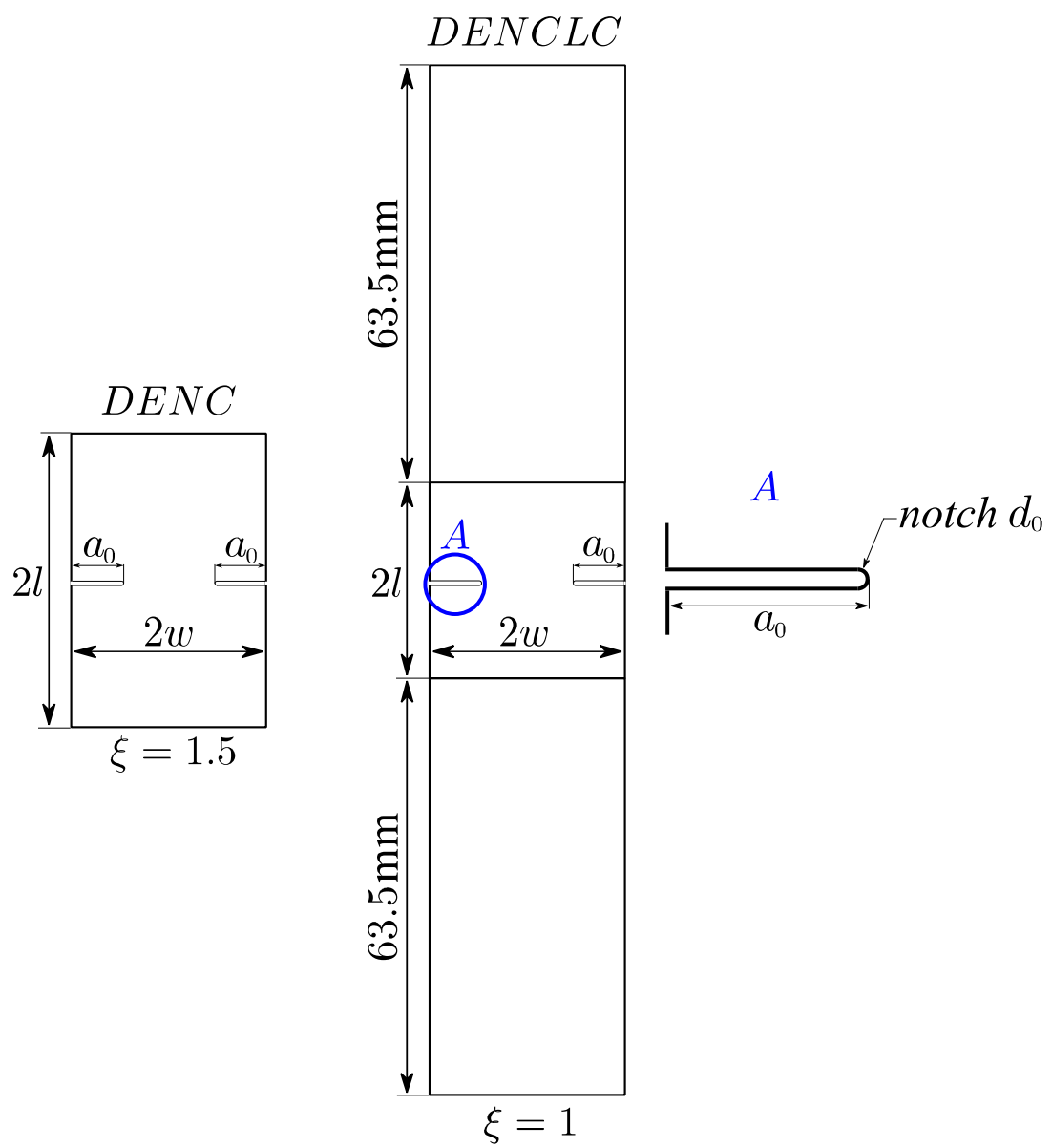

Figure 1 - DENC and DENCLC specimen geometries.

Here, $\lambda$ and $\rho$ are two dimensionless parameters that define the orthotropy of the laminate. $E_{11 C}, E_{22 C}$ are the compressive elastic moduli in the weft and warp directions, $G_{12}$ is the in-plane shear modulus, and $v_{12}, v_{21}$ are the in-plane Poisson's ratios of the weave.

The stress intensity factor is expressed as a function of a nominal stress, $\sigma$, a characteristic size, $w$, and a dimensionless correction factor, $\kappa$,

$$
K_{C}=\sigma \sqrt{w} \kappa
$$

The characteristic size was here chosen to be half the total width $(2 w)$ of each specimen. The nominal stress for a specimen of thickness $t$, was calculated as $\sigma=P /(2 w t)$. The correction factor $\kappa$ depends on the orthotropy of the laminate $(\lambda, \rho)$, and on the geometrical parameters of the specimen $(\xi=l / w$ and $\alpha=a / w)$. For the DENC specimens, the gauge length, $2 l$, was scaled according to the fixed ratio of $\xi=1.5$, while the DENCLC gauge length was scaled with $\xi=1$. The shorter gauge length of the DENCLC specimens was a consequence of the dimension limitations imposed by the standard CLC fixture. The dimensionless ratio $\alpha$ relates the crack length, $a$, to the width of the specimen. Its initial value, $\alpha_{0}=a_{0} / w$, was kept constant at 0.5 for all specimens. By maintaining a constant $\xi, \kappa$ can be determined as a sole function of $\alpha$ and $\rho$. 


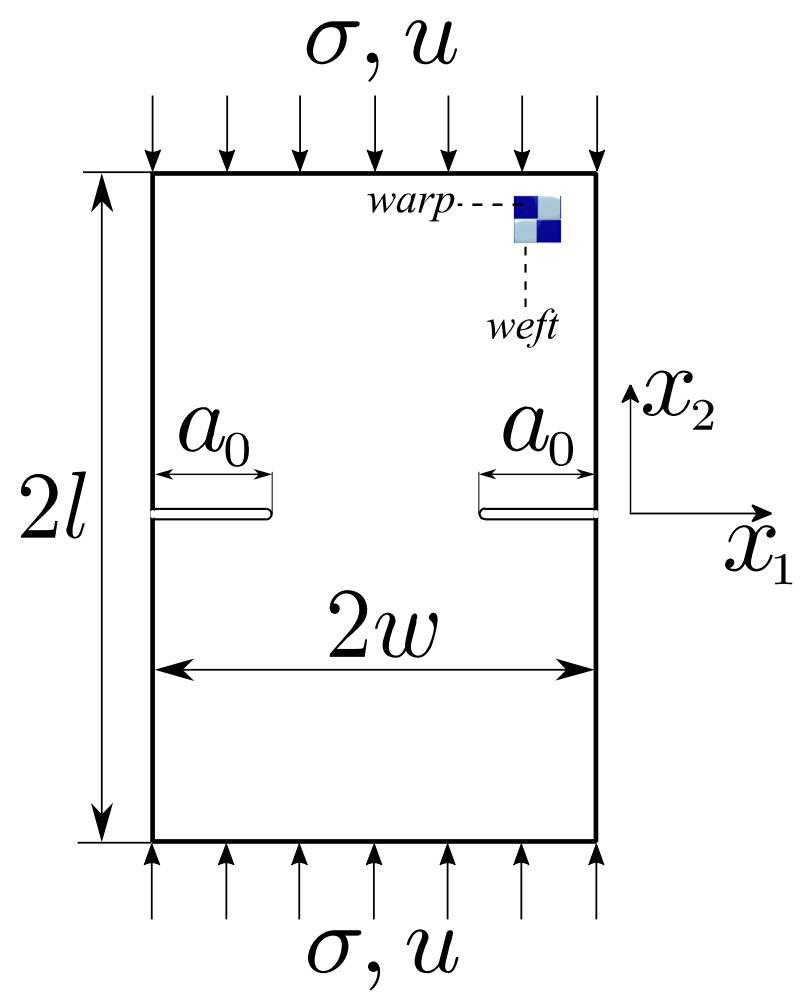

Figure 2 - Arbitrary DENC specimen geometry.

This correction factor $\kappa$ was determined numerically, by applying the Virtual Crack Closure Technique (VCCT) to a parametric FEM model, created in the commercial software package Abaqus ${ }^{\circledR}$ [31], as shown in [17].

Similar to what has been presented in literature for Mode I intralaminar fracture toughness [17], the concept of Trace Theory [32] was applied to the elastic compressive properties of several commercially available 2D woven CFRP materials. By exploiting their similarities, simplified general expressions were derived for the correction factor and the energy release rate, applicable to the majority of such balanced woven materials. A list of these material properties is found in Table 1, including the trace of the plane stiffness matrix, $\operatorname{tr}(Q)$, and two trace-normalised elastic properties: the equivalent modulus, $E^{*}$, and compressive modulus, $E_{11 C}^{*}$. Trace Theory shows that the normalised compressive elastic properties have constant values. As a result, orthotropy parameters $\lambda$ and $\rho$ should also remain relatively unchanged for such materials. For the materials investigated, the normalised elastic properties were found to be constant, with a very small coefficient of variation, CV\%. While $\lambda$ was also found to be constant $(\lambda \approx 1)$ for such balanced weaves, $\rho$ had a more significant variation, with a CV\% of 14. For the investigated materials, the $95 \%$ confidence interval was found to be $5.8 \leq \rho \leq 7.8$. 
Table 1 - Compressive elastic and orthotropic properties for commercially available and tested 2D woven CFRP composite materials.

\begin{tabular}{|c|c|c|c|c|c|c|c|c|c|c|}
\hline Material & $\begin{array}{l}E_{11 C} \\
{[\mathrm{GPa}]}\end{array}$ & $\begin{array}{l}E_{22 C} \\
{[\mathrm{GPa}]}\end{array}$ & $\begin{array}{c}G_{12} \\
{[\mathrm{GPa}]}\end{array}$ & $\begin{array}{c}v_{12} \\
{[-]}\end{array}$ & $\begin{array}{l}\operatorname{tr}(Q) \\
{[\mathrm{GPa}]}\end{array}$ & $\begin{array}{c}\dot{E} \\
{[\mathrm{GPa}]}\end{array}$ & $\begin{array}{c}\lambda \\
{[-]}\end{array}$ & $\begin{array}{l}\rho \\
{[-]}\end{array}$ & $\begin{array}{l}E^{*} \\
{[-]}\end{array}$ & $\begin{array}{c}E_{11 C}^{*} \\
{[-]}\end{array}$ \\
\hline $\begin{array}{l}\text { Tencate TC250-HTS40 } \\
\text { 12k Plain weave [33] }\end{array}$ & 55.3 & 55.4 & 3.58 & 0.039 & 118.0 & 26.56 & 1 & 7.68 & 0.23 & 0.47 \\
\hline $\begin{array}{l}\text { Cytec EP2202-T650 } \\
\text { 3k Plain weave [34] }\end{array}$ & 59.2 & 59.3 & 4.45 & 0.053 & 127.7 & 30.39 & 1 & 6.60 & 0.24 & 0.46 \\
\hline $\begin{array}{l}\text { Cytec 5320-1-T650 } \\
\text { 3k Plain weave [35] }\end{array}$ & 64.6 & 61.2 & 5.07 & 0.053 & 136.3 & 33.70 & 1.06 & 6.15 & 0.25 & 0.47 \\
\hline $\begin{array}{l}\text { Hexcel 8552-AS4 } \\
\text { 3k Plain weave [36] }\end{array}$ & 63.4 & 62.1 & 4.96 & 0.046 & 135.7 & 33.08 & 1.02 & 6.28 & 0.24 & 0.47 \\
\hline $\begin{array}{l}\text { Gurit SE 84LV-RC200T } \\
\text { 3k 2x2 Twill weave^^ [37] }\end{array}$ & 58.3 & 59.0 & 5.01 & 0.042 & 127.5 & 31.69 & 0.99 & 5.81 & 0.25 & 0.46 \\
\hline \multirow[t]{4}{*}{$\begin{array}{l}\text { Material } 1^{\wedge \wedge} \\
6 \mathrm{k}-5 \mathrm{HS} \text { weave }\end{array}$} & 61.5 & 60.3 & 3.69 & 0.030 & 129.3 & 28.50 & 1.02 & 8.22 & 0.22 & 0.48 \\
\hline & & & & & & Mean & 1.02 & 6.79 & 0.237 & 0.468 \\
\hline & & & & & & $\mathrm{SD}$ & 0.025 & 0.949 & 0.012 & 0.007 \\
\hline & & & & & & $\mathrm{CV} \%$ & 2.5 & 14.0 & 5.0 & 1.5 \\
\hline
\end{tabular}

${ }^{\wedge}$ The shear modulus was obtained from ASTM D7078 [10] standard testing.

${ }^{\wedge}$ Material 1 is a 2D woven toughened epoxy resin system, with Intermediate Modulus (IM) carbon fibres. The elastic properties were obtained from ASTM D3039 [8] and ASTM D7078 [10] standard testing.

The effect of a variation in $\rho$ on the correction factor $\kappa$ was investigated for both DENC $(\xi=1.5)$ and $\operatorname{DENCLC}(\xi=1)$ geometries (see Figure 3), for an average value of $\rho=6.8$. When considering this average value of $\rho$ (6.8) for the materials listed in Table 1, the variation in $\kappa$ was found to be a maximum of $2.9 \%$, within the $95 \%$ confidence interval $5.8<\rho<7.8$. This variation in $\kappa$ due to $\rho$ would have been reduced to less than $1 \%$ if longer specimens $(\xi>3)$ had been used [17]. However, using a high value of $\xi$ for specimens in compression would promote premature buckling. The $\xi$ value of 1.5 , and the range of sizes chosen for the DENC specimens, are equal to those already tested in literature [19,38]. In these works, specimens were cut from laminates with an equal thickness, and similar elastic properties, to those tested here. DIC and strain gauges were used to make sure there was no premature buckling. Thus, the chosen value of $\xi$ was deemed to be sufficiently small to avoid buckling. In the case of testing thinner laminates, or materials with lower elastic properties, specimens need to be monitored during tests, to confirm that buckling is still not present. 


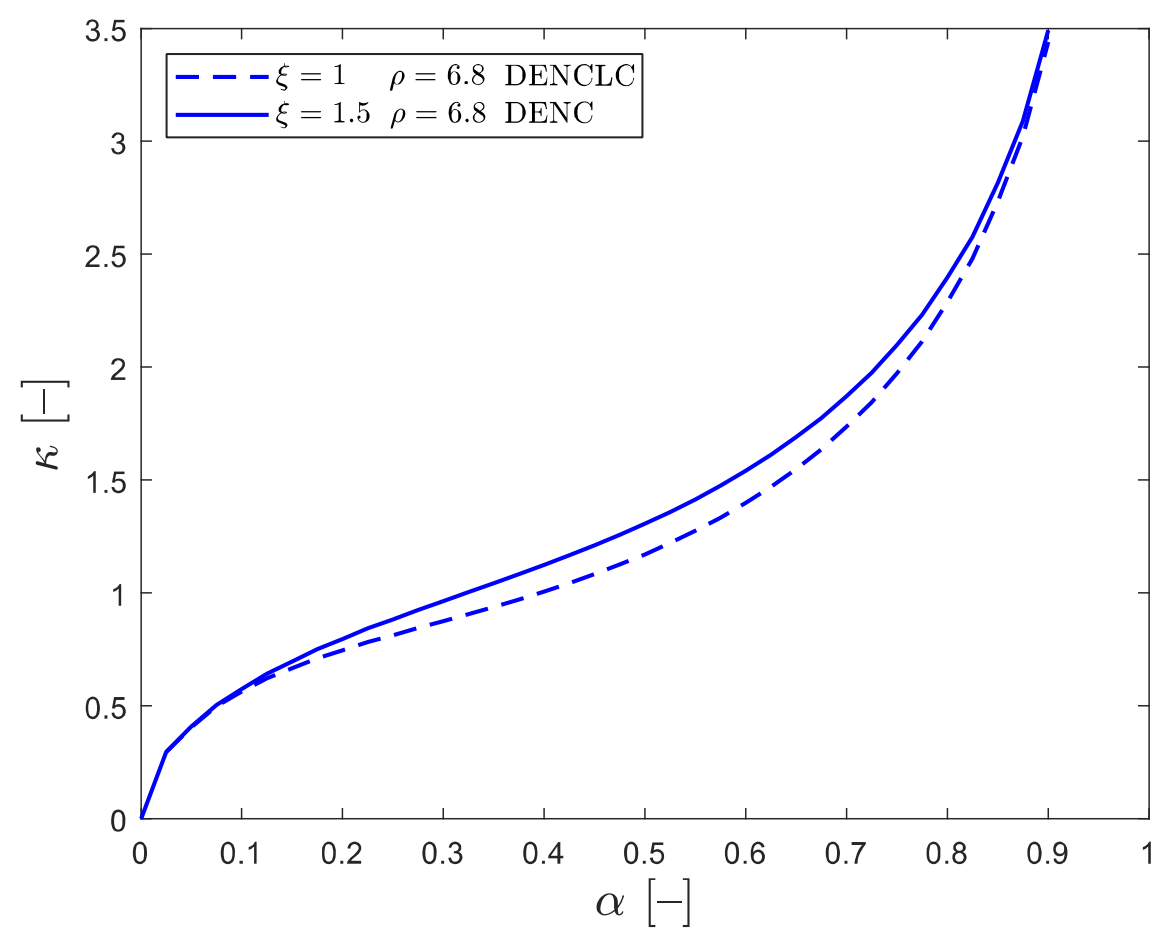

Figure 3 - Correction factor, $\kappa$, variation with specimen geometry and material orthotropy.

Using the average orthotropy value of $\rho=6.8$, the generalised expressions for the correction factor of the two specimen geometries are

$$
\begin{aligned}
& \kappa=\sqrt{\tan \left(\frac{\pi \alpha}{2}\right)}\left(0.64 \alpha^{2}-0.69 \alpha+1.5\right) \text { for } \xi=1.5, \text { DENC, } \\
& \kappa=\sqrt{\tan \left(\frac{\pi \alpha}{2}\right)}\left(1.26 \alpha^{2}-1.27 \alpha+1.5\right) \text { for } \xi=1, \text { DENCLC. }
\end{aligned}
$$

The compressive energy release rate can therefore be expressed as

$$
G_{C}=\frac{1}{E} w \sigma^{2} \kappa^{2}(\alpha)
$$

Making use of the previous observations on the trace-normalised elastic properties, where $E^{*}$ and $E_{11 C}^{*}$ can be considered constant, Eq. (7) can be reformulated as [17]:

$$
G_{C}=\frac{E_{11 c}^{*}}{E_{11 c} \dot{E}^{*}} w \sigma^{2} \kappa^{2}=\frac{2}{E_{11 c}} w \sigma^{2} \kappa^{2}
$$


where $E_{11 C}^{*} / E^{*}=0.468 / 0.237 \approx 2$ (see Table 1 ). The generalised expressions for the correction factor and energy release rate are particularly useful, helping avoid the need of recalculating $\kappa$ (using VCCT) for other 2D woven CFRPs, thus simplifying the data reduction.

The nominal stress at peak load, $\sigma_{u}$, for varying specimen sizes, follows a size effect law, $\sigma_{u}=\sigma_{u}(w)$. This law captures the transition between the strength-limit behaviour of small specimens and the Linear Elastic Fracture Mechanics (LEFM) behaviour observed in larger structures, typical of quasibrittle composite materials [24]. This size effect law can be obtained through regression fitting of the experimental peak nominal stress values for the geometrically scaled specimens. For the tested material, a bilogarithmic regression law provided the best fit of the experimental data, using a nonlinear least-squares Levenberg-Marquardt optimisation,

$$
\ln \sigma_{u}=\ln \frac{M}{\sqrt{N+w}}
$$

where $M$ and $N$ are the fitting parameters. From this size effect law, asymptotic solutions $(w \rightarrow \infty)$ can be obtained for the steady-state compressive fracture toughness, $R_{S S}$, and its critical crack tip extension, $c_{f}$, at which the fracture process zone becomes fully developed. Both these values are intrinsic material properties, and can be obtained as [24]:

$$
R_{S S}=\frac{\kappa_{0}^{2}}{\grave{E}} M^{2}, \quad c_{f}=\frac{k_{0}}{2 \hat{k}_{0}} N
$$

The critical driving force curve at peak load, $G_{C c}$, is tangential to the crack resistance curve ( $R$-curve) of the material. Furthermore, the $G_{C C}$ of each different size specimen is tangential to the $R$-curve at a distinct point. This fact is used to determine the $R$-curve as an envelope of critical crack driving force curves, as a solution of the following set of equations,

$$
\left\{\begin{array}{l}
G_{C}(\Delta a, w)=R(\Delta a) \\
\frac{\partial G_{C}(\Delta a, w)}{\partial w}=\frac{\partial R(\Delta a)}{\partial w} .
\end{array}\right.
$$

By substituting the size effect law into the first of Eq. (11), the $R$-curve can be reformulated as

$$
R(\Delta a)=\frac{2}{E_{11 c}} w \sigma^{2} \kappa^{2}\left(\alpha_{0}+\frac{\Delta a}{w}\right)
$$

Assuming that the shape parameters of the specimens are constant, including $\alpha_{0}$, and recalling that the $R$ curve is an intrinsic material property independent of specimen size $(\partial R(\Delta a) / \partial w=0)$, differentiating Eq. (12) with respect to $w$ gives 


$$
\frac{\partial}{\partial w}\left(w \sigma^{2} \kappa^{2}\right)=0
$$

Solving Eq. (13) for $w=w(\Delta a)$, and substituting $w$ back in Eq. (12), the $R$-curve can be obtained.

\subsection{Residual compressive strength $\left(X_{C r}\right)$}

According to Moran et al. [18], once the compressive strength in the fibre direction of the material is reached $\left(X_{C}\right)$, an initial kink-band is formed through localised fibre microbuckling, at which point the material response softens as the fibres in the kink-band rotate, up to the point where they lock up and break. This rotation lock up corresponds to a transition from linear material softening to a residual compressive strength, $X_{C r}$, as depicted in Figure 4.

The value of this residual compressive strength was obtained from the stable post-peak behaviour of the DENCLC specimens. The DENC specimens could not provide a stable post-peak response since the two portions of the fractured specimens were no longer aligned. The value of $X_{C r}$ was calculated as the stress observed in the fractured ligament, during the crushing process,

$$
X_{C r}=\frac{P}{2\left(w-a_{0}\right) t} .
$$

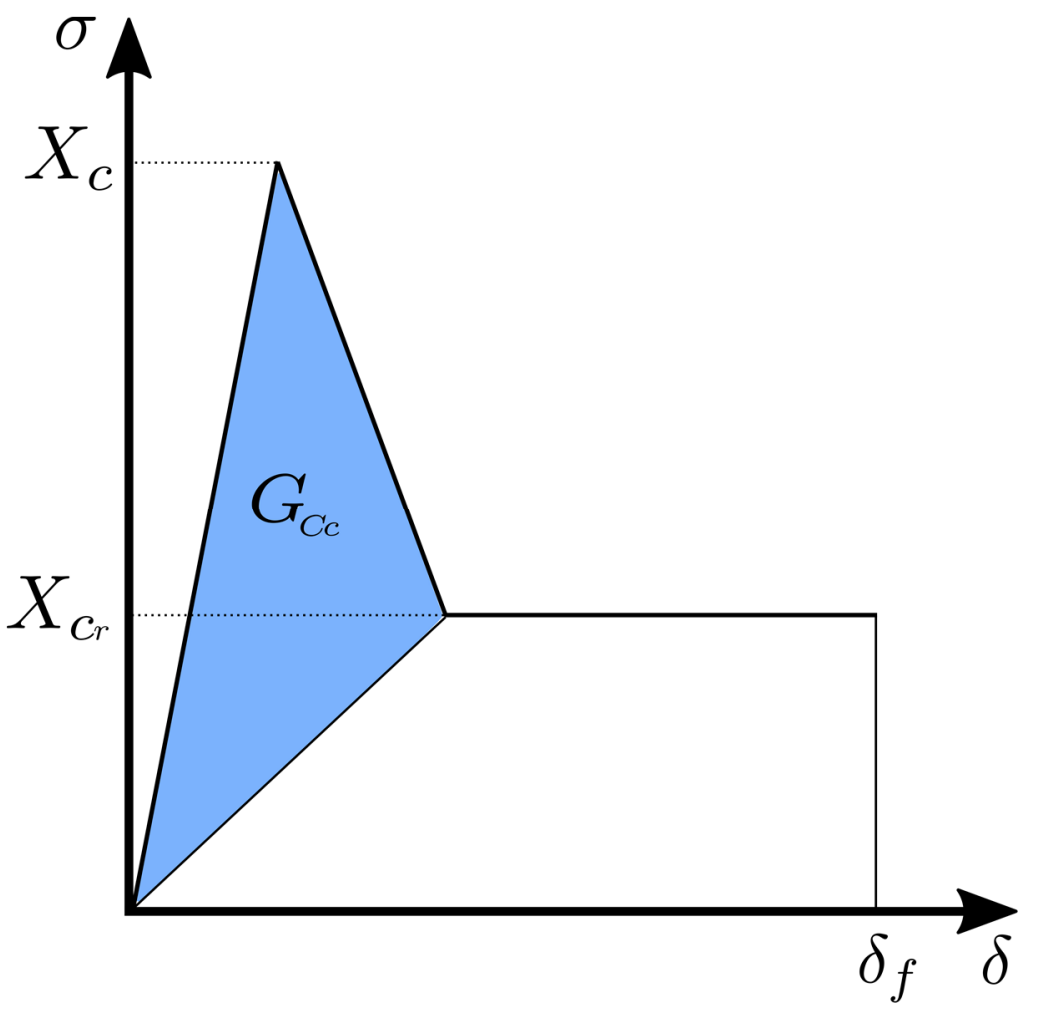

Figure 4 - Predicted stress-strain response of a 2D woven CFRP under uniaxial fibre-dominated compression. The area shaded in blue represents the compressive fracture toughness. 


\section{Material and test specimens}

The material used is a 6k-5HS woven carbon fibre reinforced epoxy, and its elastic properties are listed in Table 1, under the name "Material 1". A [0] $]_{12}$ layup was used, producing a laminate of nominal thickness 3.85 $\mathrm{mm}$. The laminates were cured in an autoclave following the recommended cure cycle. DENC and DENCLC specimens were subsequently cut in a CNC milling machine, using diamond coated cutters. The DENC specimen set had notches milled with a tip diameter $d_{0}=1 \mathrm{~mm}$, and is hereon denoted as DENC1 (Figure 5). Two sets of DENCLC specimens were cut, with $d_{0}=1 \mathrm{~mm}$ and $2 \mathrm{~mm}$, to investigate the notch tip diameter sensitivity of the peak load, and are respectively denoted as DENCLC1 (Figure 6) and DENCLC2. While six specimen sizes were tested for the DENC1 set, the two DENCLC sets were limited to five sizes, due to the dimension limitations of the CLC fixture ( $2 w=35 \mathrm{~mm}$ was not tested). A minimum of 5 specimens were tested for each size of each geometry set. Table 2 details the geometries of all the tested sets.

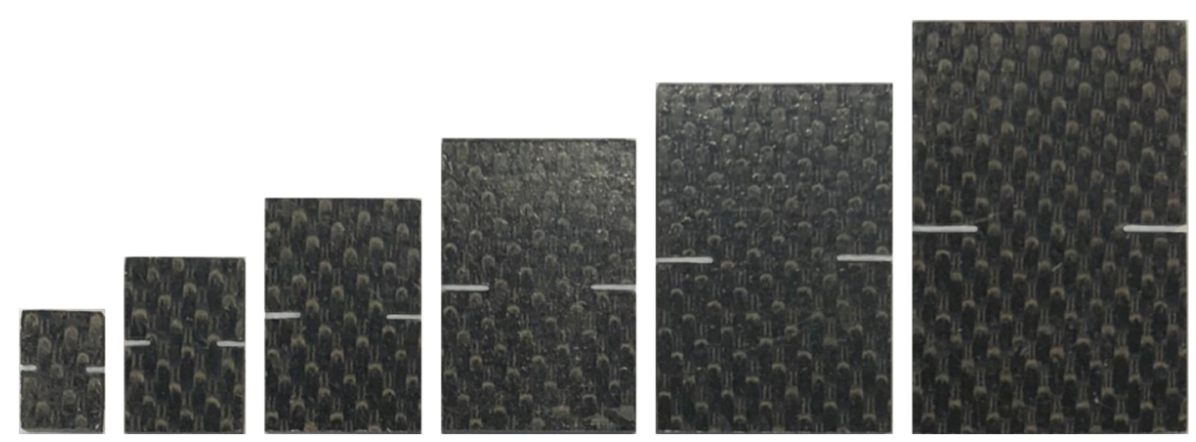

Figure 5 - DENC1 specimens.

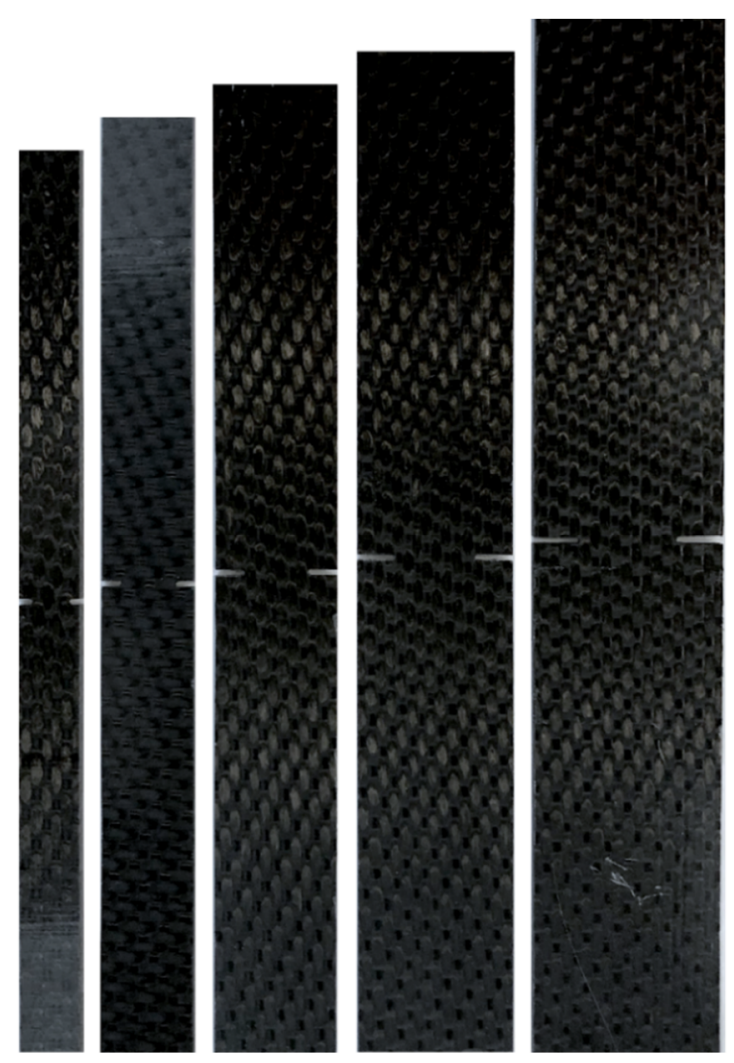

Figure 6 - DENCLC1 specimens. 


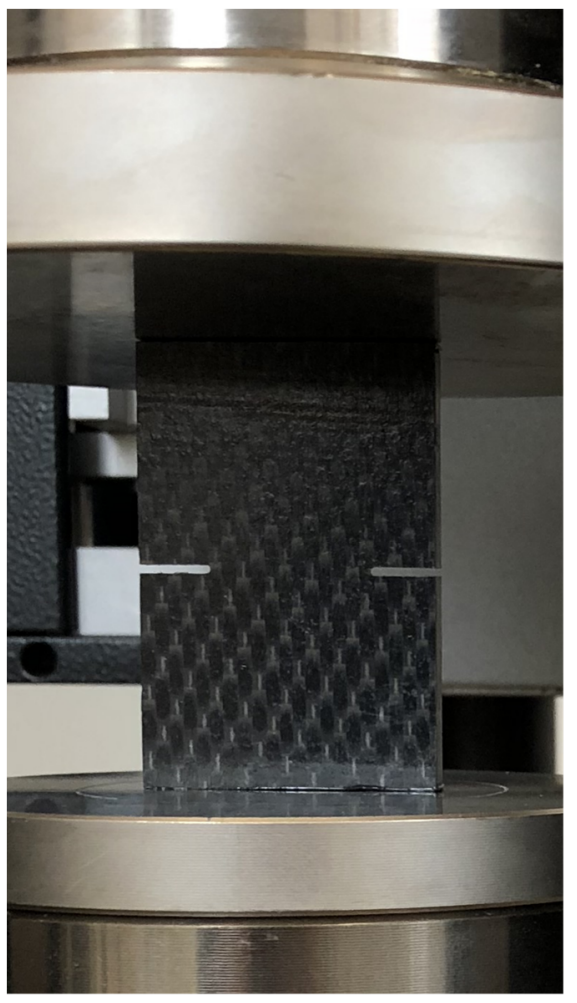

(a)

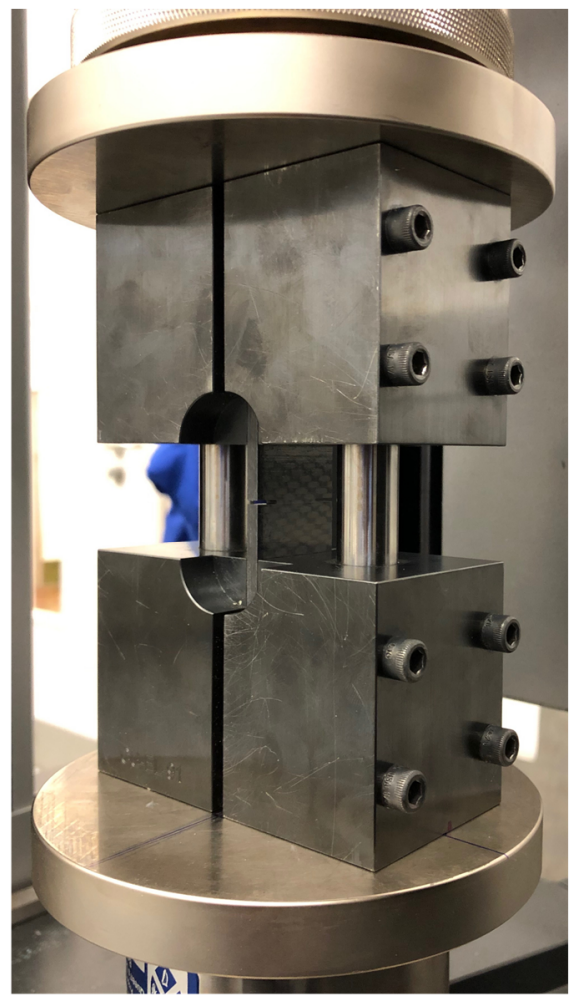

(b)

Figure 7 - Test setup: (a) DENC; (b) DENCLC.

Table 2 - DENC/DENCLC specimen geometries.

\begin{tabular}{lcccc}
\hline Specimen label & $2 w[\mathrm{~mm}]$ & $2 l[\mathrm{~mm}](\mathrm{DENC})$ & $2 l[\mathrm{~mm}](\mathrm{DENCLC})$ & $a_{0}[\mathrm{~mm}]$ \\
\hline 10 & 10 & 15 & 10 & 2.5 \\
15 & 15 & 22.5 & 15 & 3.75 \\
20 & 20 & 30 & 20 & 5 \\
25 & 25 & 37.5 & 25 & 6.25 \\
30 & 30 & 45 & 30 & 7.5 \\
35 & 35 & 52.5 & - & 8.75 \\
\hline
\end{tabular}

\section{Experimental and numerical results}

\subsection{Experimental peak load and post-peak results}

Both DENC and DENCLC specimens were tested at $1 \mathrm{~mm} / \mathrm{min}$ in a Zwick Roell Z100 test machine, using a $100 \mathrm{kN}$ load cell. The test setups for both types of geometries are shown in Figure 7. Peak nominal stresses and standard deviations were obtained for all specimen sets, and are listed in Table 3. While an evident size effect can be noted for all three sets of specimens (decreasing peak nominal stress with size), the standard deviations in peak nominal stresses for the DENC1 set are significantly larger than for the DENCLC sets, for all the tested sizes. This was attributed to a decrease in the effect of load surface imperfections (flatness and parallelism) on the behaviour of the specimen. 
Table 3 - DENC/DENCLC average peak nominal stress, $\sigma_{u}$ (in MPa), and its standard deviation (in brackets) for all tested sizes.

\begin{tabular}{lcccccc}
\hline Specimen label & 10 & 15 & 20 & 25 & 30 & 35 \\
\hline \multirow{2}{*}{ DENC1 } & 175.3 & 172.2 & 150.5 & 156.8 & 152.7 & 129.5 \\
& $(16.3)$ & $(25.9)$ & $(12.9)$ & $(15.0)$ & $(14.2)$ & $(8.1)$ \\
& & & & & \\
DENCLC1 & 198.3 & 179.8 & 170.8 & 154.2 & 157.0 & - \\
& $(4.7)$ & $(7.8)$ & $(6.7)$ & $(7.1)$ & $(6.9)$ & \\
DENCLC2 & & & & & & \\
& 203.3 & 191.2 & 176.5 & 167.0 & 161.0 & - \\
\hline
\end{tabular}

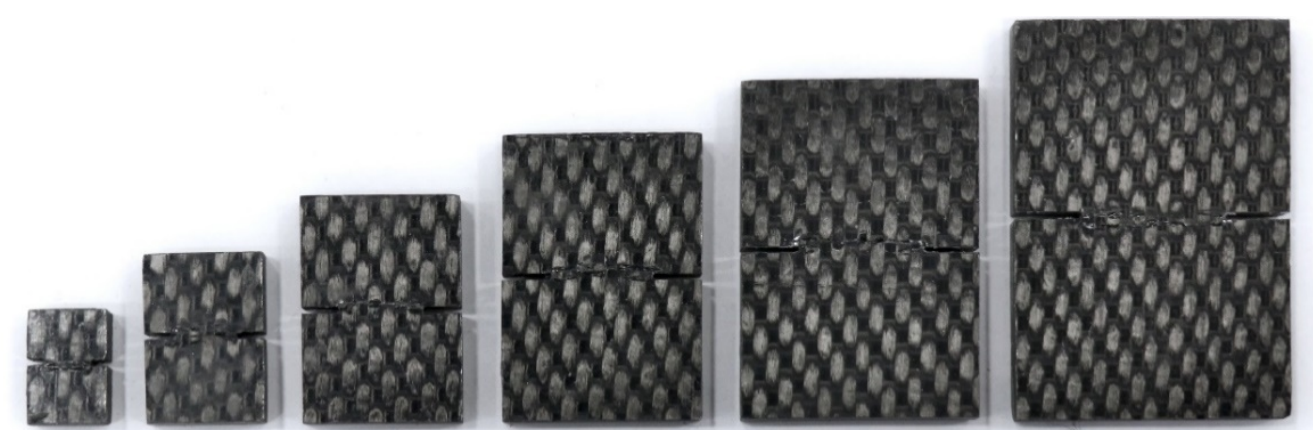

Figure 8 - Fractured DENC1 specimens.

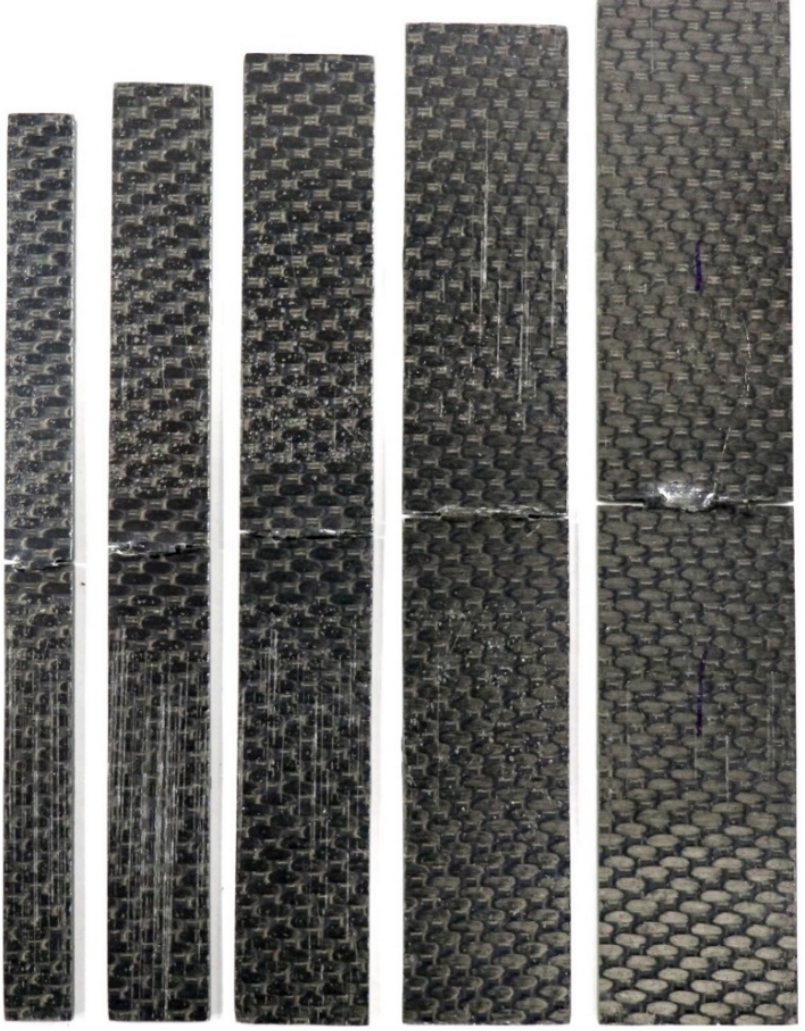

Figure 9 - Fractured DENCLC1 specimens. 
Figure 8 and Figure 9 show the fractured DENC1 and DENCLC1 specimens. The kink-band propagation in all specimens had a through-thickness inclination. In woven composites, this angle is a result of the aforementioned fibre rotation lockup angle, ply offsets, weave architecture and layup orientation [18,39]. Due to this through-thickness inclination angle of the propagated kink-band, the crack in one of the two outer plies of a specimen can lie outside of the initial ligament height between the machined notches, as shown in the front and rear views of the same fractured DENC1 and DENCLC1 specimens in Figure 10 and Figure 11. In the front image, all specimens present a crack (highlighted in orange) within the original ligament height, while in the rear image the crack in the specimens with $1 \mathrm{~mm}$ notches lies outside this ligament height. These figures also show that the propagated crack in DENCLC2 specimens was contained within the initial ligament height through the whole thickness of the specimen. Since unstable crack propagation occurs at peak load, the postpeak development of the crack outside the original ligament height should not affect the measured peak load values. However, any measurements made after this crack propagation, such as the post-peak crushing load, are influenced by the location of the developed crack.
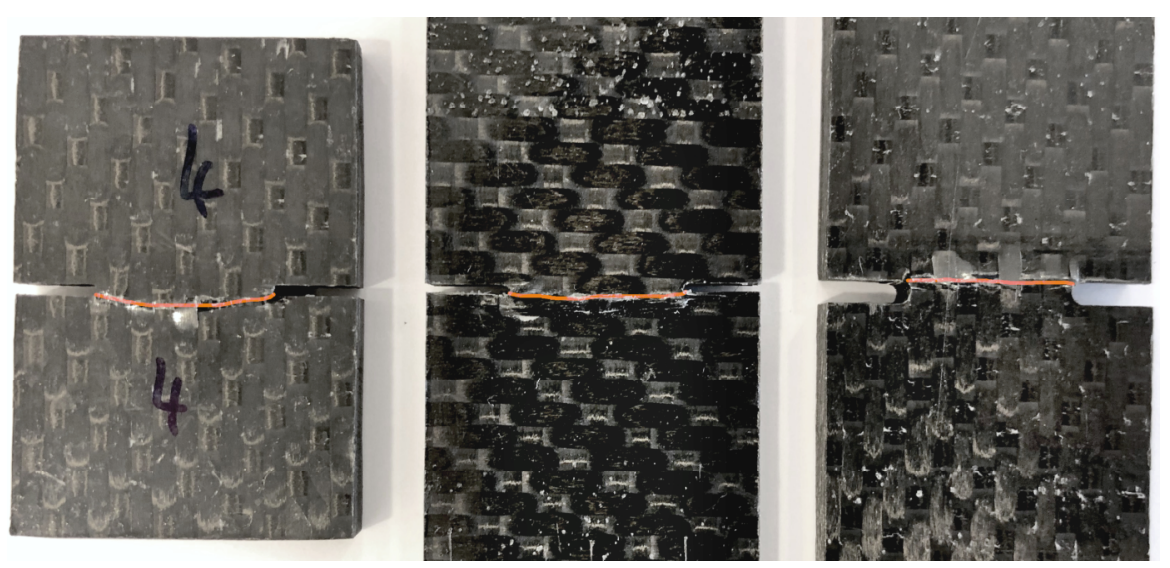

Figure 10 - Front view of fractured ligaments (crack in orange) for DENC1 (left), DENCLC1 (centre) and DENCLC2 (right) specimens.

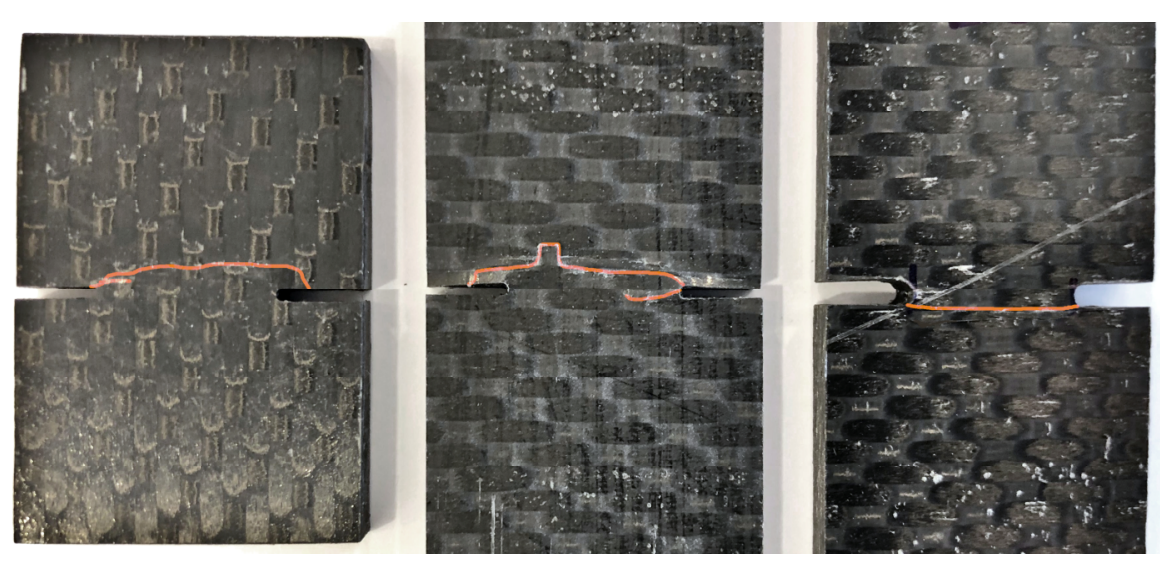

Figure 11 - Rear view of fractured ligaments (crack in orange) for DENC1 (left), DENCLC1 (centre) and DENCLC2 (right) specimens. 


\subsection{Numerical results on notch tip diameter sensitivity}

The effect of the notch tip diameter on the peak load of the specimen was also analysed numerically, by comparing the qualitative and quantitative results of two DENCLC Finite Element (FE) models, with different notch tip diameters, i.e. $d_{0}=1 \mathrm{~mm}$ and $d_{0}=2 \mathrm{~mm}$, generated using the software package Abaqus ${ }^{\circledR}$ [31]. Similar to the numerical comparison in [17], each model consists of an embedded cell (EC) surrounded by a homogenised mesoscale (ply-level) volume. The EC consists of a [0] $]_{12}$ plain weave stack, embedded in an epoxy matrix. A plain weave was modelled instead of the 5HS being tested experimentally, in order to reduce the computational cost. However, the width of the individual tows $(2 \mathrm{~mm})$ is consistent between the experiments and the simulations. The homogenised volume is used to represent the linear-elastic behaviour of the composite far from the crack region. Figure 12 shows a representation of the FE models, subjected to the appropriate Boundary Conditions (BCs), simulating a virtual test of a DENCLC specimen. The width and thickness of the virtual DENCLC specimens are $2 w=20 \mathrm{~mm}$, and $t=3.2 \mathrm{~mm}$, respectively, while the overall length is 147 $\mathrm{mm}$.

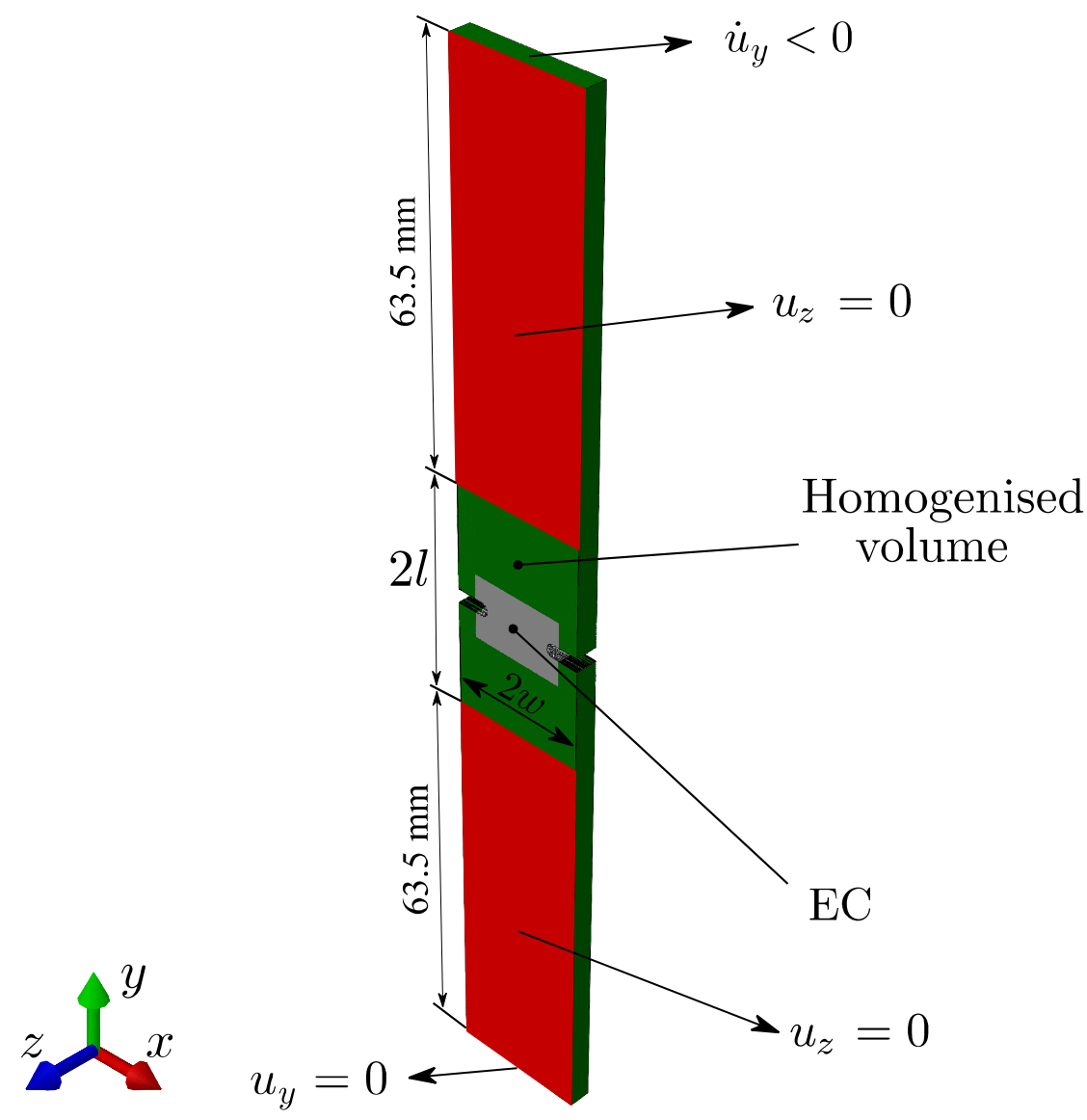

Figure 12 - FE model of the DENCLC specimen, including the embedded cell (EC) and homogenised volume, with the applied BCs.

\subsubsection{Pre-compaction simulation of the Embedded Cell}

Following [40], the tows of the EC were randomly disposed, and then pre-compacted in order to obtain a representative value of the fibre volume fraction of the material (see Figure 13 right), generating a more realistic representation of a cured composite laminate. Two analytical rigid bodies were used as compression plates for 
the pre-compaction simulation, including a general explicit contact formulation, with a penalty friction approach to avoid interpenetration between yarns. During this compaction stage, the dry tows were assumed to have a linear-elastic transversely isotropic behaviour, and modelled using fully integrated 3D hexahedral elements (C3D8) in order to maintain a realistic tow geometry during compaction (avoiding hourglass deformations). Finally, in order to force periodicity on the outer shape of the ECs, the models were subjected to 2D Periodic Boundary Conditions (PBCs) $[40,41]$. The overall in-plane dimensions of the EC were: $L_{E C}=10 \mathrm{~mm}$ and $W_{E C}=15 \mathrm{~mm}$ (see Figure 13 left), with a final thickness of $3.2 \mathrm{~mm}$ after the compaction process.

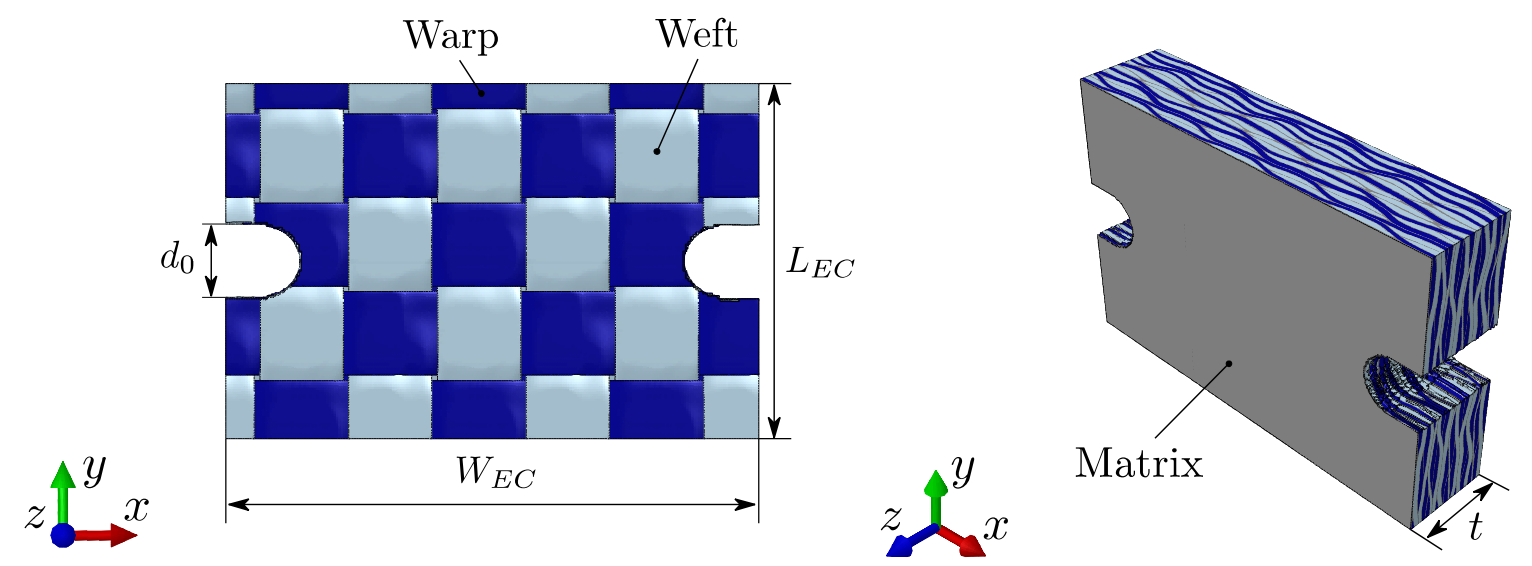

Figure 13 - Embedded Cell isometric representation (right), and a front view highlighting the weave pattern (left).

\subsubsection{DENCLC specimen simulation}

Through orphan mesh capabilities, the homogenised volume of the specimen was generated by extruding 100 solid layers at each of the compacted boundaries of the EC. The hexahedral elements, used for the tows during compaction, were exchanged for their reduced integration version (C3D8R), allowing the tows to be assigned the intralaminar damage model for the specimen simulation. Similarly, the homogenised volume was also discretised using C3D8R elements. The complex volumes existing between the compacted tows of the EC, representing matrix resin pockets within the weave, were discretised using $3 \mathrm{D}$ tetrahedral solid elements (C3D4). The elements in the EC had an average size of $0.03 \mathrm{~mm}$. The notches were created by removing elements along the centreline of each specimen, ensuring that $\alpha_{0}=0.5$ was the same for both FE models, as shown in Figure 14.

\subsubsection{Material models}

The stress localisation due to the notches ensured that damage initiated and propagated within the EC. Therefore, the homogenised volume was assumed to behave in a simple orthotropic linear-elastic manner, helping reduce the total computational cost of the FE simulations.

The compacted tows were modelled using a transversely isotropic intralaminar damage model, originally developed by the Advanced Composites Research Group (ACRG) at Queen's University Belfast (QUB) [4244]. The behaviour of the material in the three principal directions is modelled as linear elastic up to failure, while shear deformations follow nonlinear inelastic laws. The model, implemented as a VUMAT subroutine in 
Abaqus $^{\circledR}$, uses strain-based damage initiation functions to predict damage initiation along the fibre direction, and a modified version of the Puck and Schürmann [45] failure criterion to capture the transverse and throughthickness matrix dominated damage initiation [46]. Different damage variables were used to represent the evolution of damage in the material, each corresponding to a different failure mechanism. The model also makes use of an advanced way to calculate the characteristic element length and a non-linear damage model for inelastic deformation, stiffness degradation, and load reversal. For more information, the reader is referred to $[42-44,47]$.
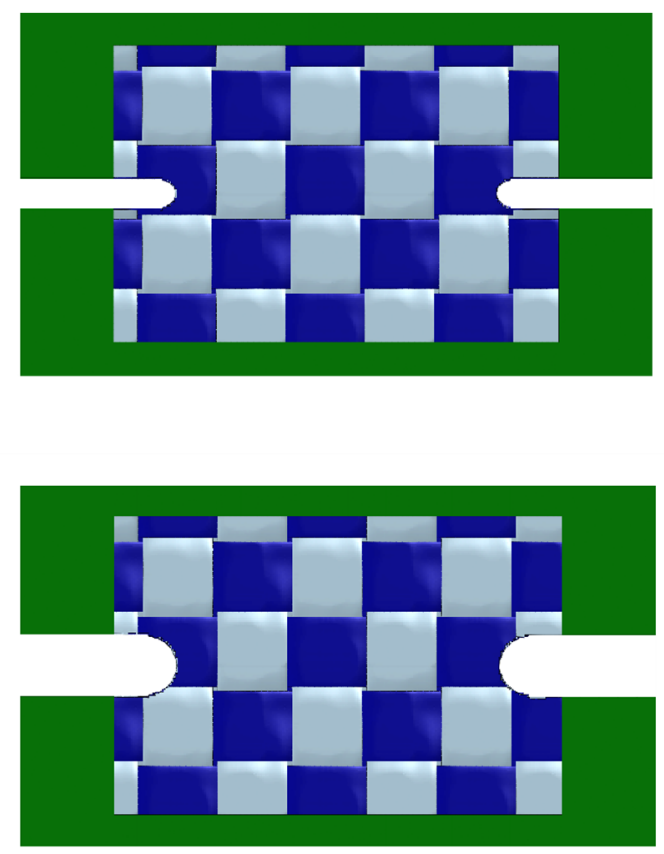

Figure 14 - Representation of the initial notch tip within the EC, $d_{0}=1 \mathrm{~mm}$ (top), and $d_{0}=2 \mathrm{~mm}$ (bottom).

The resin in the EC was modelled using an isotropic elasto-plastic damage model originally proposed by Melro et al. [48]. The behaviour of the material is assumed to be elastic until a paraboloidal yield criterion is met [49]. The constitutive model also accounts for pressure dependency and different yield strengths in tension and compression. A damage model defined by a single damage variable is used, where damage initiation is defined by a damage activation function similar to the paraboloidal yield criterion. Mesh dependency is avoided through the regularisation of the dissipated energy, using the characteristic element length and the mode I fracture toughness of the resin [50]. For the sake of brevity, the model is not completely described here. For more information, the reader is referred to $[48,51]$ for a detailed description of the constitutive material model.

Since the outcome of these two simulations was only used to compare the peak loads obtained for specimens with different notch tip diameters, the input material properties can be considered to have a minimal effect on the comparative results. Thus, elastic and strength properties used to model both constituents were assumed to be the ones obtained by Melro et al. [41]. Table 4 and Table 5 list the material properties of the epoxy matrix and tows. The elastic properties considered for the homogenised volume are the ones reported for Material 1 in Table 1. 
Table 4 - Epoxy matrix material properties

\begin{tabular}{cc}
\hline Mechanical property & Epoxy matrix \\
\hline Elastic modulus & $E^{m}=3760 \mathrm{MPa}$ \\
Poisson's ratio & $v^{m}=0.39$ \\
Tensile strength & $X_{T}^{m}=93 \mathrm{MPa}$ \\
Compressive strength & $X_{C}^{m}=180 \mathrm{MPa}$ \\
Mode I fracture toughness & $G_{I C}^{m}=0.09 \mathrm{~kJ} / \mathrm{m}^{2}$ \\
\hline
\end{tabular}

Table 5 - Tow material properties

\begin{tabular}{cc}
\hline Mechanical property & Tows \\
\hline Elastic moduli & $E_{11}^{T}=138910 \mathrm{MPa} ; E_{22}^{T}=E_{33}^{T}=9380 \mathrm{MPa}$ \\
Poisson's ratios & $v_{12}^{T}=v_{13}^{T}=0.245 ; v_{23}^{T}=0.350$ \\
In-plane shear modulus & $G_{12}^{T}=5080 \mathrm{MPa}$ \\
Longitudinal tensile strength & $X_{T}^{T}=2057 \mathrm{MPa}$ \\
Longitudinal compressive strength & $X_{C}^{T}=1200 \mathrm{MPa}$ \\
Transverse tensile strength & $Y_{T}^{T}=68 \mathrm{MPa}$ \\
Transverse compressive strength & $Y_{C}^{T}=123 \mathrm{MPa}$ \\
Shear strengths & $S_{12}^{T}=S_{13}^{T}=48 \mathrm{MPa} ; S_{23}^{T}=39 \mathrm{MPa}$ \\
Mode I longitudinal intralaminar fracture toughness & $G_{I C}^{1 T}=101.5 \mathrm{~kJ} / \mathrm{m}^{2}[15]$ \\
Compressive longitudinal intralaminar fracture toughness & $G_{C c}^{1 T}=61 \mathrm{~kJ} / \mathrm{m}^{2}[19]$ \\
Mode I transverse intralaminar fracture toughness & $G_{I C}^{2 T}=0.2 \mathrm{~kJ} / \mathrm{m}^{2 \mathrm{a}}$ \\
Compressive transverse intralaminar fracture toughness & $G_{C c}^{2 T}=0.4 \mathrm{~kJ} / \mathrm{m}^{2 \mathrm{a}}$ \\
Mode II intralaminar fracture toughness & $G_{I I C}^{12 T}=G_{I I C}^{13 T}=G_{I I c}^{23 T}=0.4 \mathrm{~kJ} / \mathrm{m}^{2 \mathrm{a}}$
\end{tabular}

${ }^{a}$ Estimated

Damaged elements were removed throughout the simulations, to avoid excessive element distortion which could trigger early termination. This deletion was performed using the following computational strategy:

$$
\text { Delete element if }=\left\{\begin{array}{c}
d_{m}>0.999 \\
d_{11}^{C}>0.999 \\
\operatorname{det} \boldsymbol{F} \leq 0.5 \vee \operatorname{det} \boldsymbol{F} \geq 2.0
\end{array}\right. \text {, }
$$

where $d_{m}$ and $d_{11}^{C}$ are, respectively, the damage variable of the matrix constituent and the fibre-dominated compressive damage variable of the tows. The det $\boldsymbol{F}$ value represents the ratio between the deformed and undeformed volume of an element. 


\subsubsection{DENCLC specimen simulation results}

Figure 15 shows the quantitative numerical predictions of both DENCLC virtual specimens, normalised with respect to the higher of the two failure stresses, and its corresponding displacement. Four points are highlighted (A to D) throughout the load-displacement curves. These points correspond to different stages of the compressive intralaminar crack propagation, as represented in Figure 16 and Figure 17. These contour plots present the fibre compressive damage variable $\left(d_{11}^{C}\right)$ within the tows, for the two notch tip diameters.

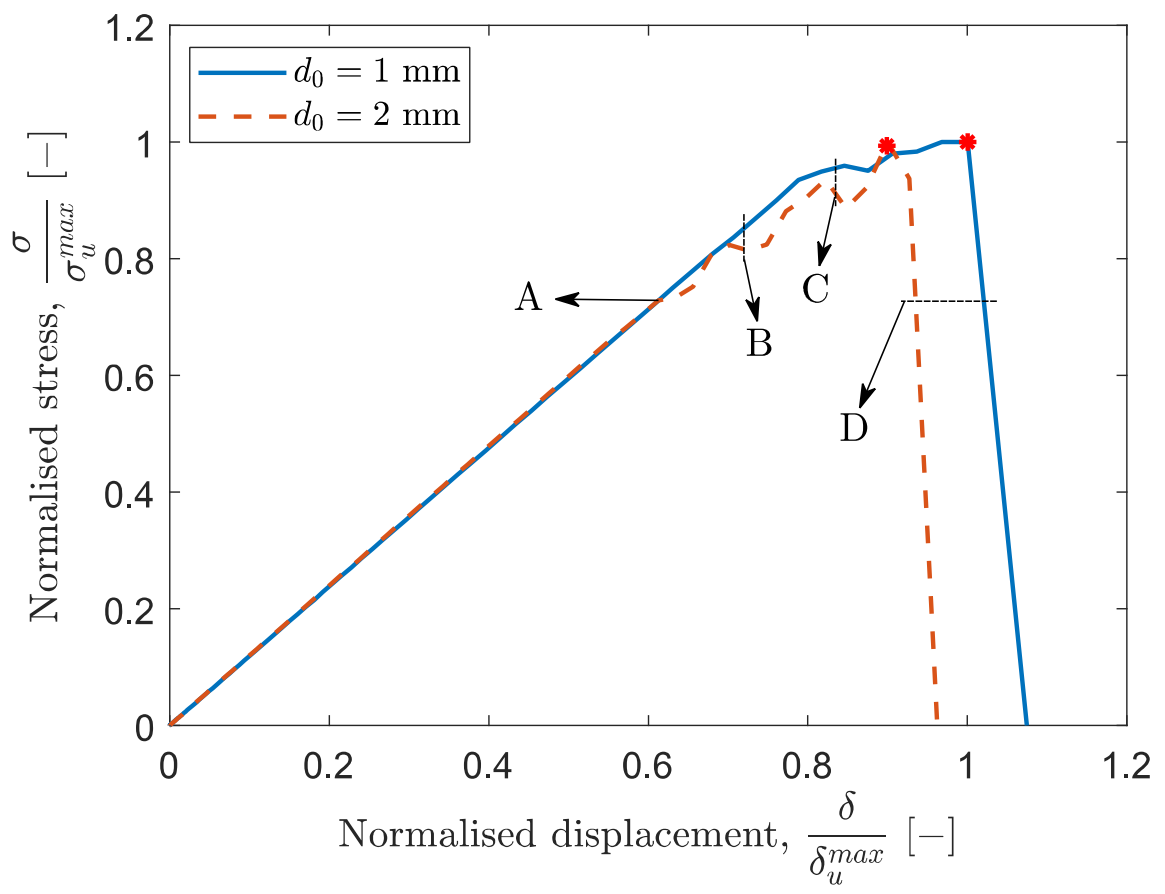

Figure 15 - Normalised nominal stress - displacement curves for the DENCLC FE models, highlighting four distinct points.
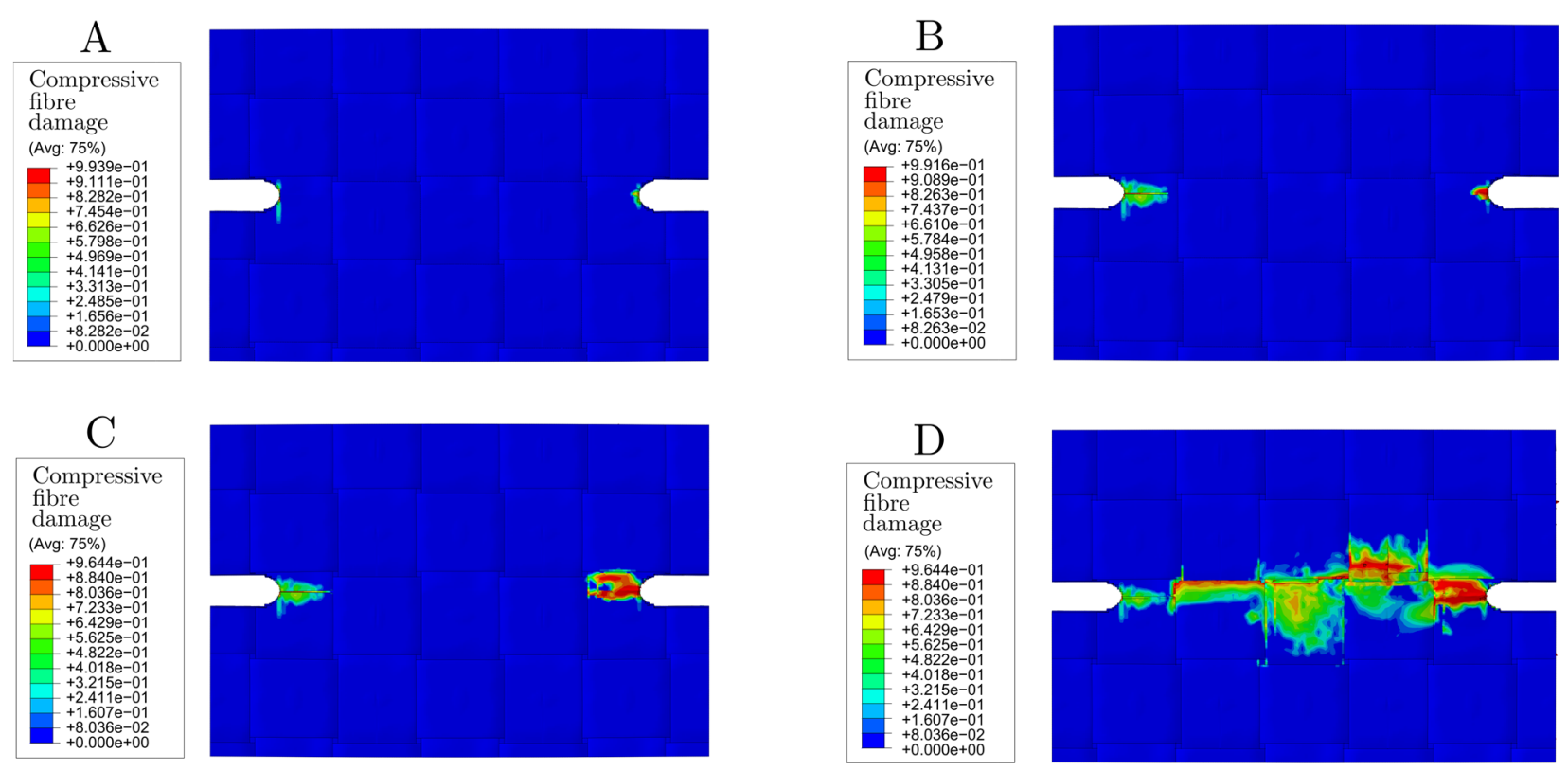

Figure 16 - Fibre compressive damage and crack propagation through the EC volume corresponding to the four distinct points (A-D) in the load displacement curve, for the smaller notch diameter specimen $\left(d_{0}=1 \mathrm{~mm}\right)$. 

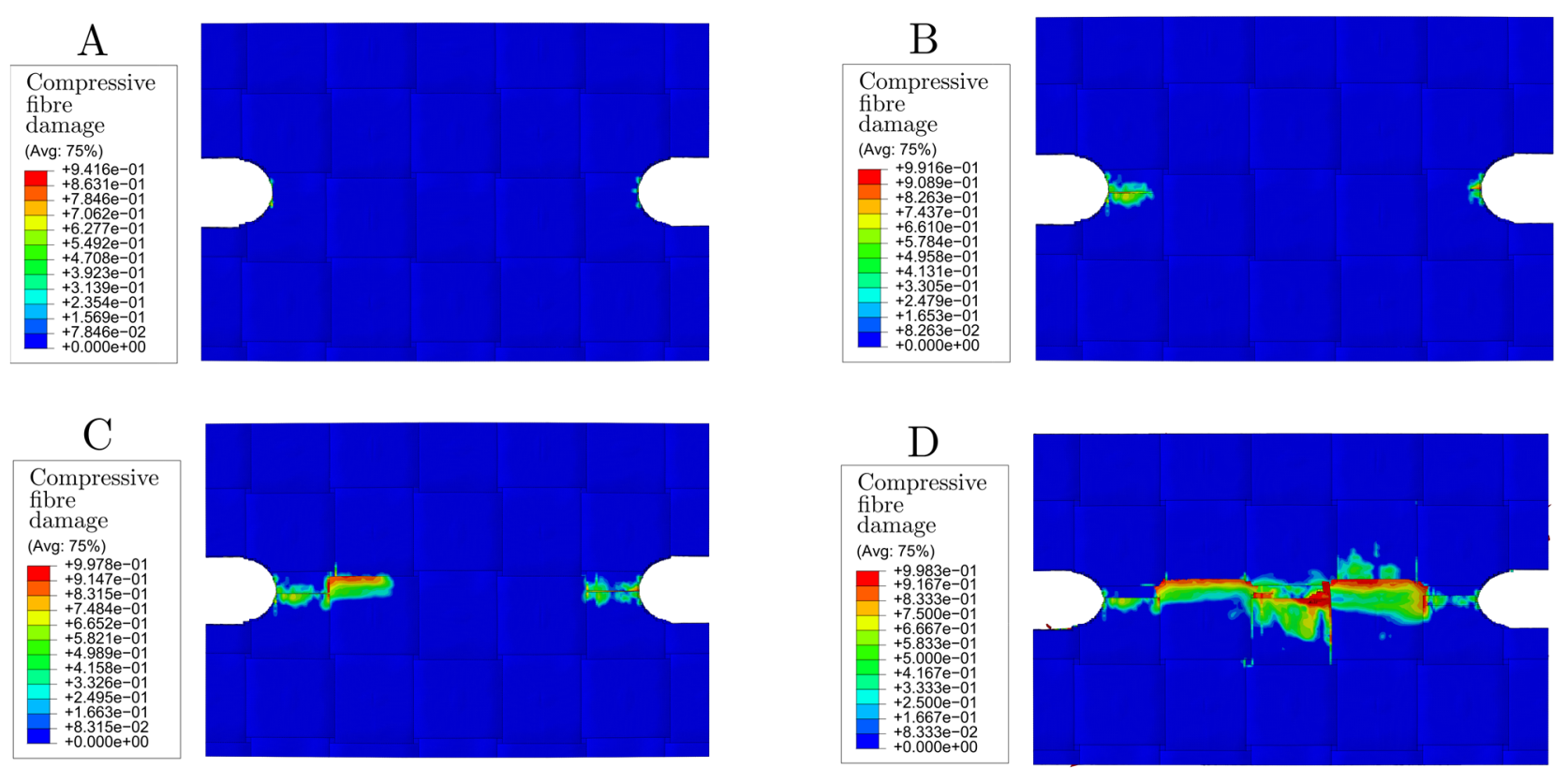

Figure 17 - Fibre compressive damage and crack propagation through the EC volume corresponding to the four distinct points (A-D) in the load displacement curve, for the larger notch diameter specimen $\left(d_{0}=2 \mathrm{~mm}\right)$.

The ordinate value of the plot presented in Figure 15 represents the ratio between the current stress, $\sigma$, and the maximum nominal stress of the two curves, $\sigma_{u}^{\max }$, while the abscissa value represents the ratio between the current displacement, $\delta$, and the maximum displacement of the two curves, $\delta_{u}^{\max }$. The four points identified portray: (A) slight fibre damage at the initial notch tip; (B) crack propagation in the outer plies of the EC; (C) advanced crack propagation throughout the EC, including preferential crack localisation at the edges of warp tows; (D) unstable intralaminar crack propagation after peak load. The difference between peak loads for these two specimens was shown to be very small. From both qualitative numerical predictions (Figure 16 and Figure 17), the cracks developed before peak load were contained within the initial ligament height $\left(d_{0}\right)$, in-between the initial notches, making the quantitative predictions valid up to unstable crack propagation. 


\section{Compressive fracture toughness and residual strength}

5.1 Compressive fracture toughness $\left(G_{C c}\right)$

The bilogarithmic size effect law of Eq. (9) was fitted to the experimental peak nominal stress data for each of the three specimen sets (Table 3). The fits for each set can be observed in Figure 18, including the corresponding $95 \%$ confidence intervals. A larger variation was observed in the DENC1 specimen data when compared to the two DENCLC sets. The downward shift of the size effect law fitting for the DENC1 set, when compared to the DENCLC sets (Figure 18d), can be attributed to the larger correction factor value, $\kappa$, of the DENC geometry (Figure 3). The difference between the fits of the two DENCLC sets is not significantly different. The fit coefficients $(M, N)$, and the $R$-curve parameters $c_{f}$ and $R_{S S}$, for all specimen sets, are listed in Table 6.

The $R$-curve for each set of specimens is depicted in Figure 19, including their respective $95 \%$ confidence intervals, and an overall comparison. These confidence intervals were derived from their corresponding intervals obtained for the size effect laws. Both the DENC and DENCLC specimens produced similar $R$-curves and $R_{S S}$ values. However, the $95 \%$ confidence interval for the DENC set was significantly wider than the two DENCLC sets. Hence, the use of DENCLC specimens is recommended. Furthermore, since the $R_{S S}$ value of the DENCLC2 set falls within the 95\% confidence interval of the DENCLC1 set, it was concluded that, even if the size effect law for the DENCLC2 specimen is higher than that of the DENCLC1, the measured fracture toughness of the former falls within the $95 \%$ confidence intervals of the latter. This conclusion cannot be extended to specimens with larger notch diameters, where the measured peak loads could be higher, artificially increasing the calculated fracture toughness. The steady-state fracture toughness, $R_{s S}$, obtained here for $2 \mathrm{D}$ woven composites $(32.5$ $\mathrm{kJ} / \mathrm{m}^{2}$ ), is comparable to the laminate level fracture toughness measured for Hexcel IM7-8552 cross-ply UD composites using the size effect method $\left(30.5 \mathrm{~kJ} / \mathrm{m}^{2}\right)[19]$.

Table 6 - Size effect law fitting parameters, critical crack extension and steady-state fracture toughness.

\begin{tabular}{lcccc}
\hline Specimen label & $M[\mathrm{MPa} \sqrt{\mathrm{mm}}]$ & $N[\mathrm{~mm}]$ & $c_{f}[\mathrm{~mm}]$ & $R_{S S}\left[\mathrm{~kJ} / \mathrm{m}^{2}\right]$ \\
\hline DENC1 & 771.4 & 13.8 & 4.39 & 33.8 \\
DENCLC1 & 760.4 & 10.0 & 3.21 & 28.3 \\
DENCLC2 & 815.6 & 11.0 & 3.53 & 32.5 \\
\hline
\end{tabular}




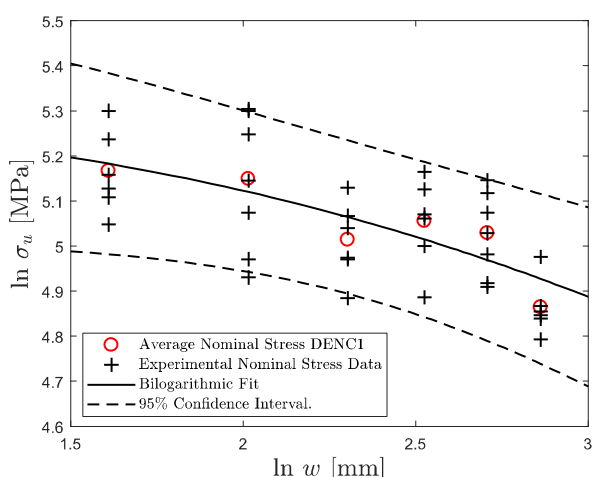

(a)

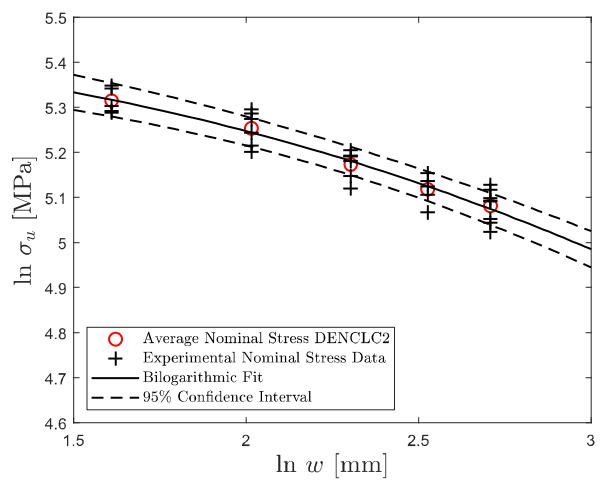

(c)

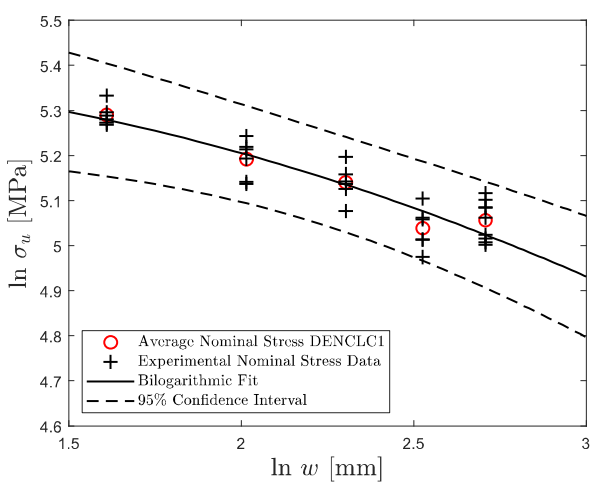

(b)

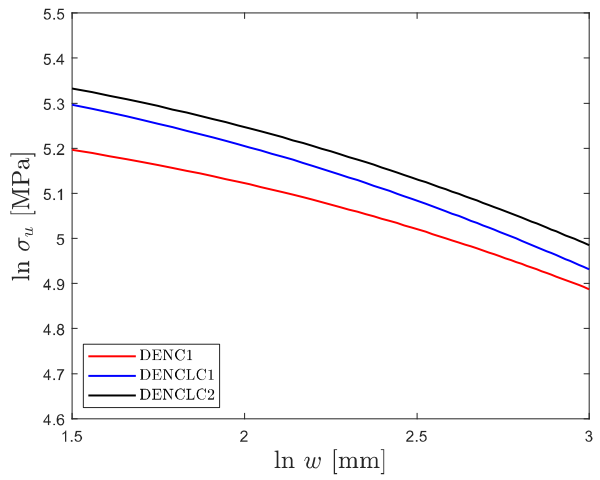

(d)

Figure 18 - Size effect laws: (a) DENC1; (b) DENCLC1; (c) DENCLC2; (d) Comparison.

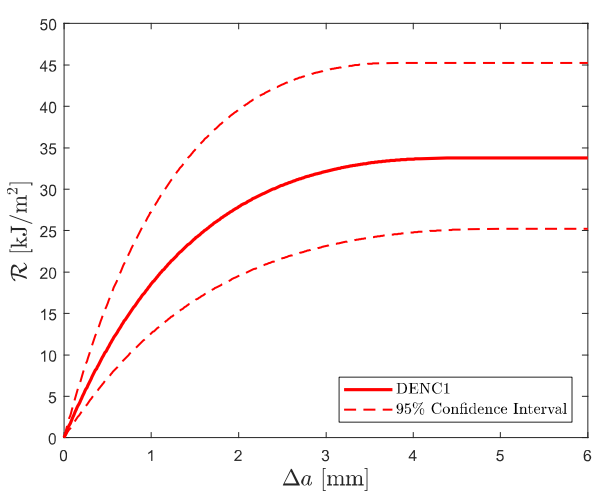

(a)

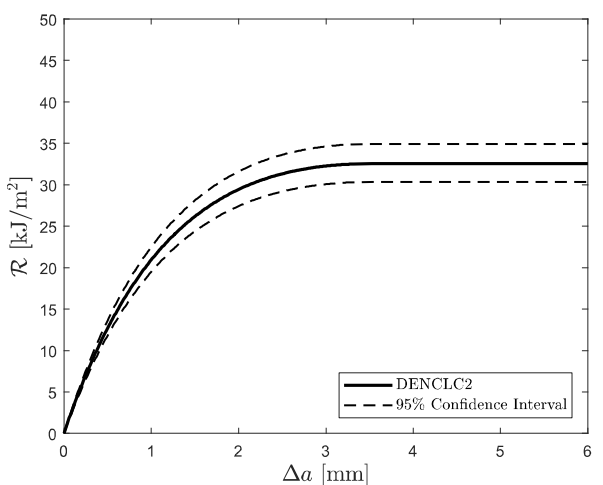

(c)

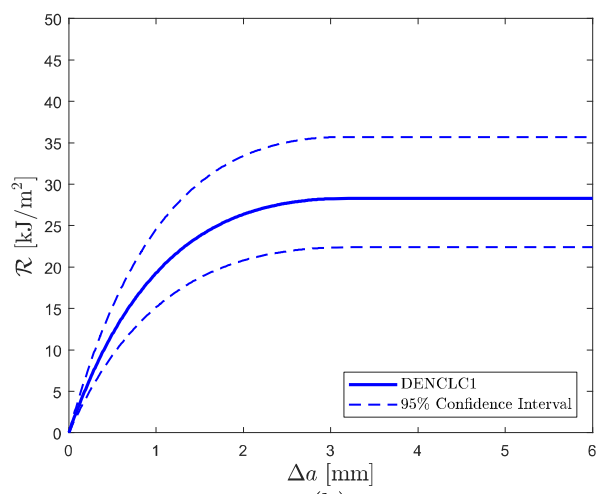

(b)

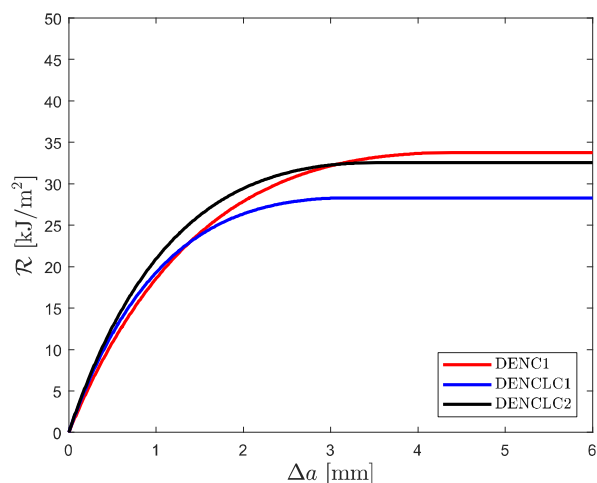

(d)

Figure 19 - R-curves: (a) DENC1; (b) DENCLC1; (c) DENCLC2; (d) Comparison. 


\subsection{Residual compressive strength $\left(X_{C r}\right)$}

The post-peak crack propagation of the DENCLC2 specimen set was contained within the initial ligament height, unlike the propagation observed in the other two specimen sets. Moreover, the two portions of the fractured specimens were kept aligned by the CLC fixture after peak load (Figure 20). Thus, only the DENCLC2 specimens were considered valid for the calculation of the residual compressive strength. Furthermore, to better capture the material variability arising from weave architecture and ply offsets, only the largest specimens $(2 w=30 \mathrm{~mm})$ of the DENCLC2 set were considered here.

The post-peak crushing behaviour for this set of specimens was found to stabilise (Figure 21), progressing until the two faces of the initial notch came into contact, at which point the load started to increase again. The crushing stress for these specimens was calculated along the ligament of length $w=15 \mathrm{~mm}$, using Eq. (15). The compressive residual strength $\left(X_{C r}\right)$ was calculated as the average crushing stress observed from all eight specimens in this set, over a crushing length of $1 \mathrm{~mm}$, between the stabilisation after peak load and the second rise in load. Figure 22 indicates a significant variability in the crush stress observed for the eight specimens. This is a result of the different crack band morphologies that developed after the peak load of each specimen. The kink-band inclination through the thickness of the specimen depended on the location of the individual kink-band failure of each ply. While some specimens developed a smooth kink-band that transected through all plies (Figure 23), other specimens developed multiple kink-band inclinations throughout their thickness (Figure 24). The four specimens which crushed in a similar manner to Figure 23 provided a higher crushing stress than the other four which failed similarly to Figure 24. This difference was attributed to the greater amount of delaminations observed during the latter type of crushing behaviour, which reduced the crushing load of such specimens. This delamination occurred when wedges on one half of the cracked specimen were forced into the opposite half, as shown in Figure 24.

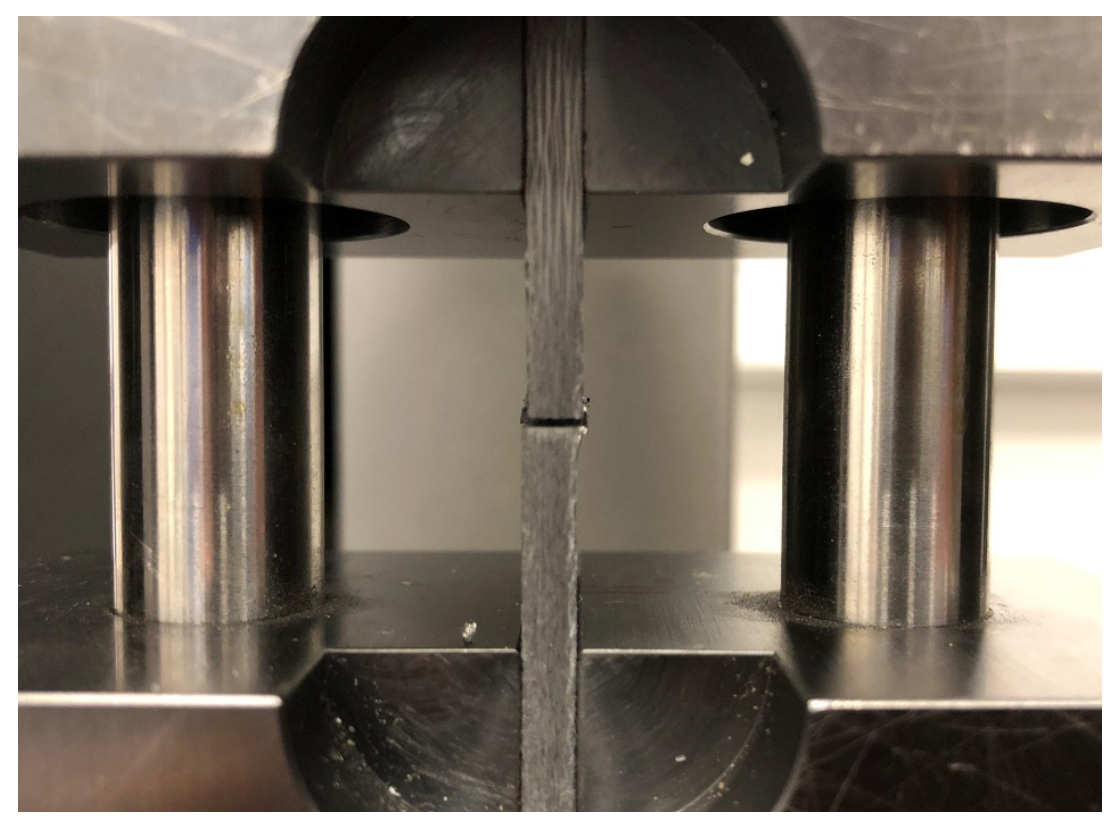

Figure 20 - DENCLC specimen alignment after peak load (side view). 


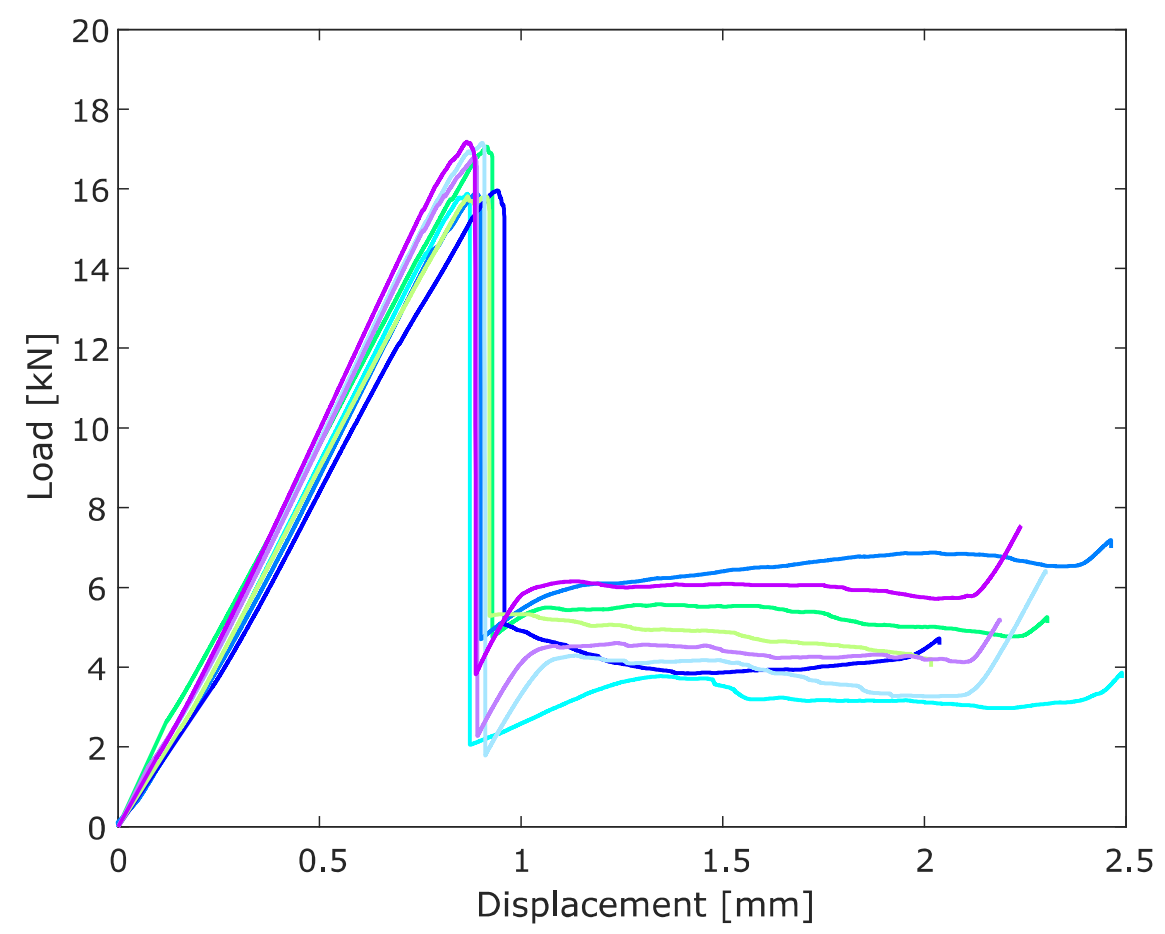

Figure 21 - Load-displacement curves for eight DENCLC2 specimens, $2 w=30 \mathrm{~mm}$.

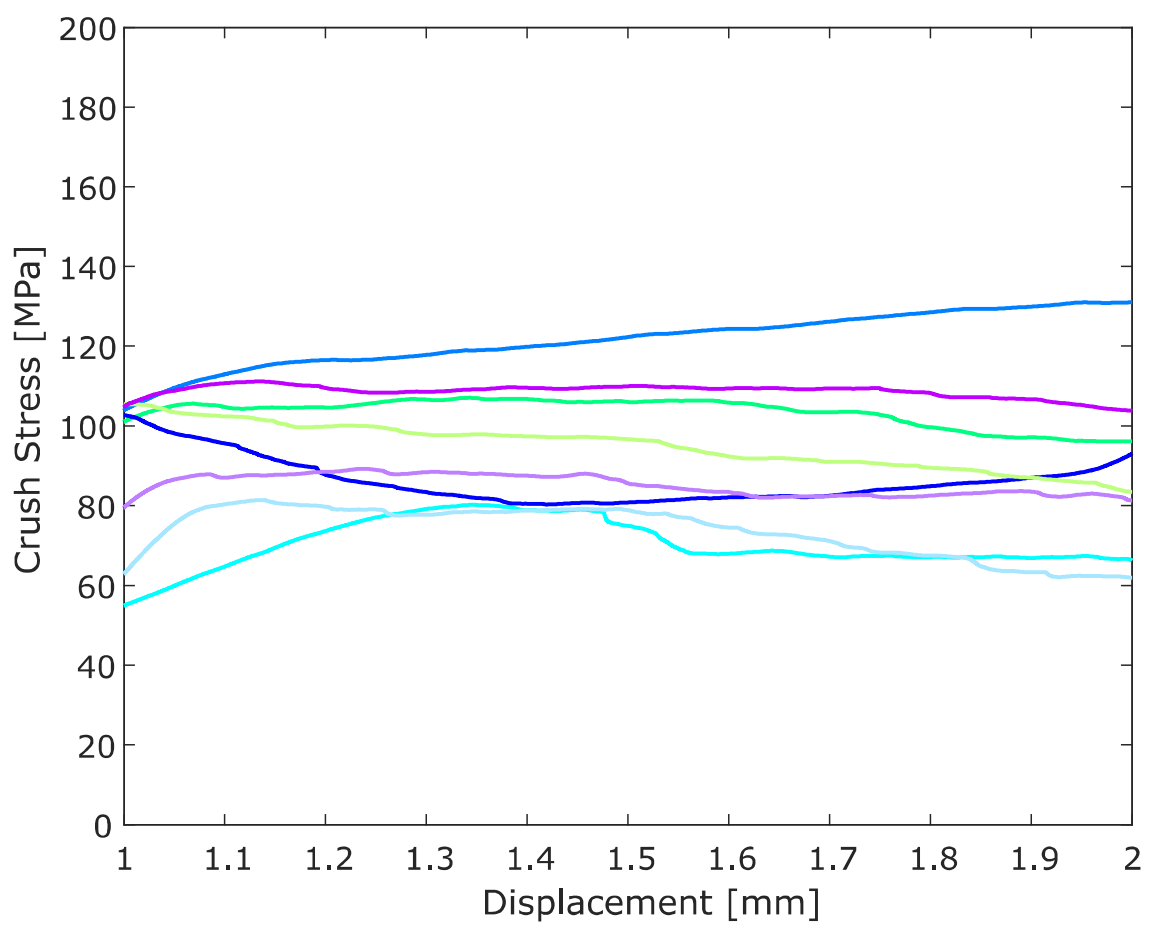

Figure 22 - Crush stress variation of eight DENCLC2 specimens, $2 w=30 \mathrm{~mm}$.

In total, four specimens failed in a similar manner to Figure 23, with an average crush stress of 103.9 MPa (standard deviation of 3.8 MPa). The other four specimens, which failed similar to Figure 24, had an average crush stress of 81.6 MPa (standard deviation of 6.1 MPa). Considering that all specimens failed through the formation of inclined through-thickness kink-bands, albeit with some differences in morphology, the averaging of the crush stress of all eight specimens was deemed an accurate way of taking the different morphologies into 
account when calculating the residual compressive stress. This average value was calculated to be $X_{C r}=92.7$ $\mathrm{MPa}$ (standard deviation of 17.0 MPa).

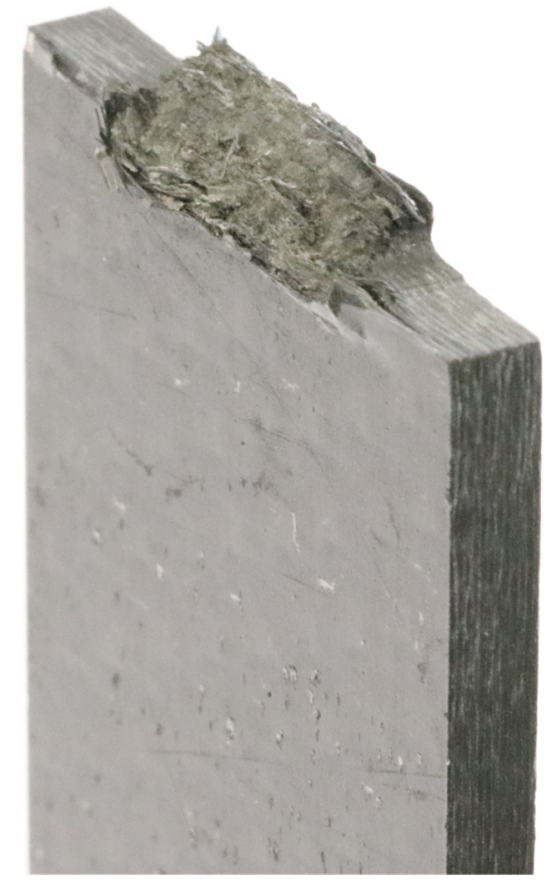

(a)

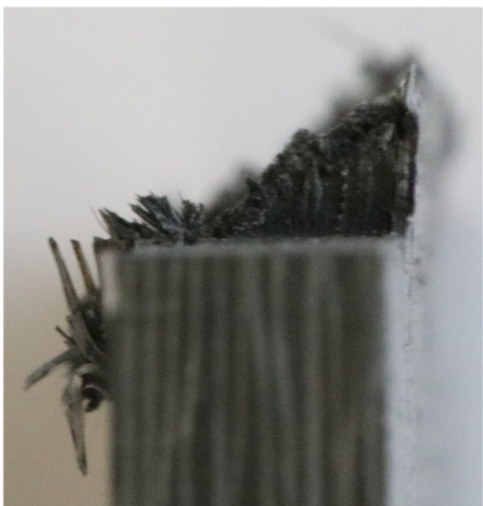

(b)

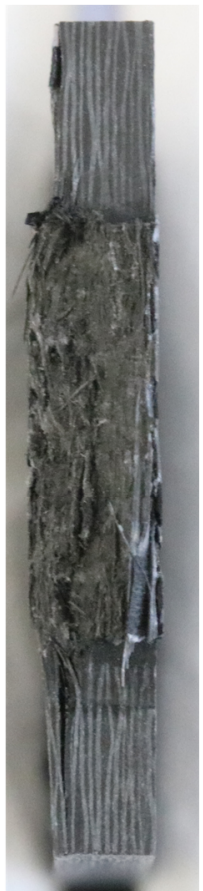

(c)

Figure 23 - Crush surface of a DENCLC2 specimen failing with a smooth kink-band inclination: (a) isometric; (b) side; and (c) top views.

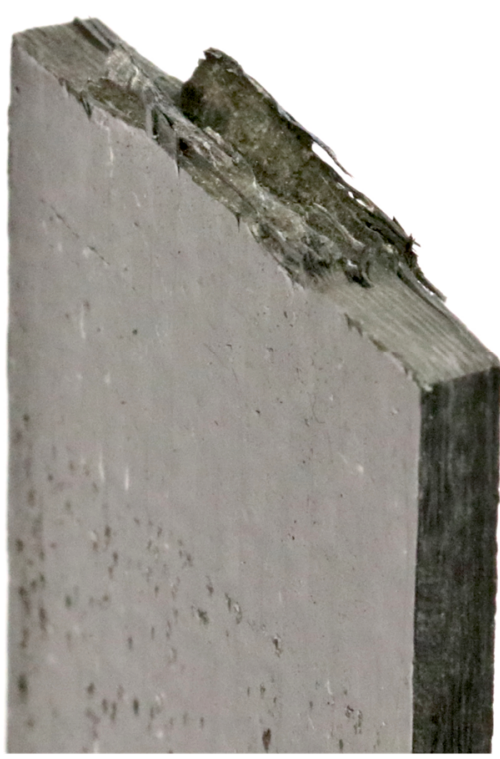

(a)

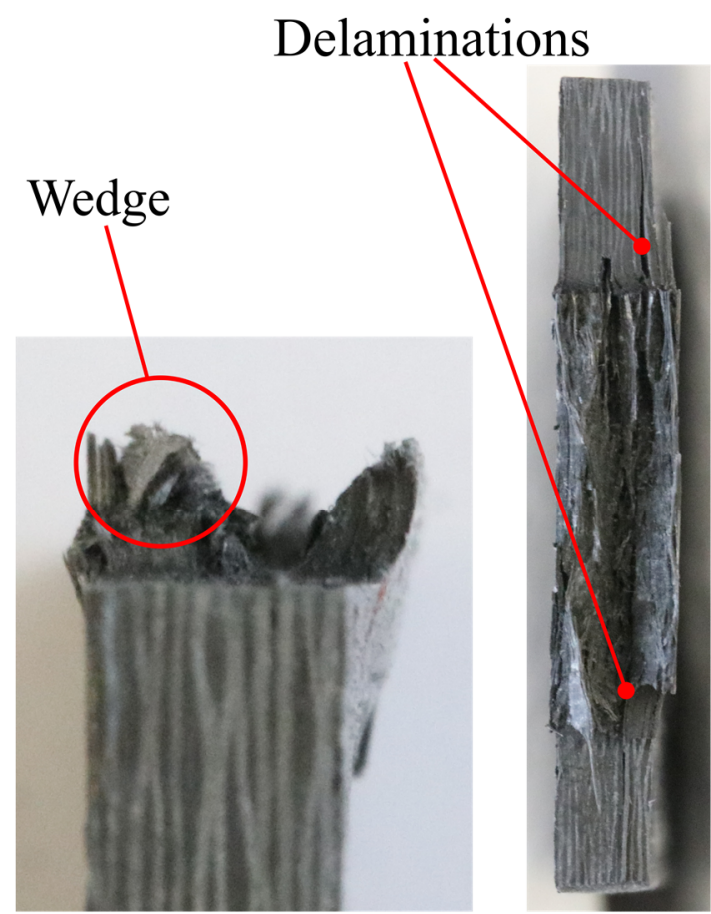

(b)

(c)

Figure 24 - Crush surface of a DENCLC2 specimen failing with multiple kink-band inclinations: (a) isometric; (b) side; and (c) top views. 


\section{Conclusions}

A careful comparison of experimental results of both Double Edge Notch Compression (DENC) and Double Edge Notch Combined Loading Compression (DENCLC) specimens, as well as the numerical results of the notch sensitivity study, reveal the following conclusions:

- DENCLC specimens provided a distinct improvement on the original DENC geometry, by reducing the scatter in peak loads, hereby improving the accuracy of the results. Although the compressive fracture toughness calculated from both types of geometry is similar, the confidence interval for the DENCLC specimens is significantly smaller. The use of DENCLC specimens could provide a similar improvement in measuring the compressive fracture toughness of UD laminates.

- The experimental and numerical studies on DENCLC specimens have shown that within the two tested notch tip diameters, there is no significant difference in the measured fracture toughness. However, this conclusion cannot be extended to future experiments with larger notch tip diameters, where the measured fracture toughness might be artificially increased.

- Similar to what has been developed for mode I intralaminar fracture toughness [17], the data reduction scheme presented for the size effect method has been further simplified through the application of Trace Theory, and made applicable to most commercially available 2D woven composites. This simplification eliminates the need of further orthotropic corrections for this class of materials, and consequently the recalculation of the correction factor through FEM analysis.

- The use of DENCLC specimens, with an initial notch tip diameter of $2 \mathrm{~mm}$, enabled the calculation of the residual compressive strength of the material, by virtue of the stable post-peak crushing observed in such specimens.

This study has further developed the size effect method proposed for compressive fracture toughness, and applied it to $2 \mathrm{D}$ woven composites, to obtain both their fibre-dominated compressive fracture toughness and residual compressive strength. Furthermore, the developments presented here have provided an increased accuracy in results, and a data reduction technique which can be more easily applied to a wide class of materials, paving the way for future standardisation of this experimental method.

\section{Acknowledgements}

The authors gratefully acknowledge the financial support of the project ICONIC - Improvement of Crashworthiness of Composite Transportation Structures. ICONIC has received funding from the European Union`s Horizon 2020 research and innovation programme under the Marie Skłodowska-Curie grant agreement 
No 721256. The content reflects only the author's view and the Agency is not responsible for any use that may be made of the information it contains.

\section{References}

[1] Maimí P, Camanho PP, Mayugo JA, Dávila CG. A continuum damage model for composite laminates: Part I - Constitutive model. Mechanics of Materials 2007;39:897-908. doi:10.1016/j.mechmat.2007.03.005.

[2] Donadon M V, Iannucci L, Falzon BG, Hodgkinson JM, Almeida SFM De. A progressive failure model for composite laminates subjected to low velocity impact damage 2008;86:1232-52. doi:10.1016/j.compstruc.2007.11.004.

[3] Falzon BG, Apruzzese P. Numerical analysis of intralaminar failure mechanisms in composite structures. Part I: FE implementation. Composite Structures 2011;93:1039-46. doi:10.1016/j.compstruct.2010.06.028.

[4] Falzon BG, Apruzzese P. Numerical analysis of intralaminar failure mechanisms in composite structures. Part II: Applications. Composite Structures 2011;93:1047-53. doi:10.1016/j.compstruct.2010.06.022.

[5] Raimondo L, Iannucci L, Robinson P, Curtis PT. A progressive failure model for mesh-size-independent FE analysis of composite laminates subject to low-velocity impact damage. Composites Science and Technology 2012;72:624-32. doi:10.1016/j.compscitech.2012.01.007.

[6] Tan W, Falzon BG, Chiu LNS, Price M. Predicting low velocity impact damage and Compression-AfterImpact (CAI) behaviour of composite laminates. Composites Part A 2015;71:212-26. doi:10.1016/j.compositesa.2015.01.025.

[7] Liu H, Falzon BG, Tan W. Experimental and numerical studies on the impact response of damagetolerant hybrid unidirectional/woven carbon-fibre reinforced composite laminates. Composites Part B: Engineering 2018;136:101-18. doi:10.1016/j.compositesb.2017.10.016.

[8] ASTM. D3039/D3039M-17 Standard Test Method for Tensile Properties of Polymer Matrix Composite Materials. 2017. doi:10.1520/D3039_D3039M-08.

[9] ASTM. D6641/D6641-14 Standard Test Method for Compressive Properties of Polymer Matrix Composite Materials Using a Combined Loading Compression ( CLC ) 2012. doi:10.1520/D6641_D6641M-14.

[10] ASTM. D7078/D7078M -12 Standard Test Method for Shear Properties of Composite Materials by VNotched Rail Shear Method. 2012. doi:10.1520/D7078_D7078M-12.

[11] ASTM. D5528-13 Standard Test Method for Mode I Interlaminar Fracture Toughness of Unidirectional Fiber-Reinforced Polymer Matrix Composites 2015. doi:10.1520/D5528-13.2.

[12] ASTM. D6671/D6671M-19 Standard Test Method for Mixed Mode I-Mode II Interlaminar Fracture 
Toughness of Unidirectional Fiber Reinforced Polymer Matrix Composites 2019. doi:10.1520/D6671_D6671M-19.

[13] ASTM. D7905/D7905M-14 Standard Test Method for Determination of the Mode II Interlaminar Fracture Toughness of Unidirectional Fiber-Reinforced Polymer Matrix Composites 2014. doi:10.1520/D7905_D7905M-14.

[14] Donadon M V., Falzon BG, Iannucci L, Hodgkinson JM. Intralaminar toughness characterisation of unbalanced hybrid plain weave laminates. Composites Part A: Applied Science and Manufacturing 2007;38:1597-611. doi:10.1016/j.compositesa.2006.12.003.

[15] Catalanotti G, Arteiro A, Hayati M, Camanho PP. Determination of the mode I crack resistance curve of polymer composites using the size-effect law. Engineering Fracture Mechanics 2014;118:49-65. doi:10.1016/j.engfracmech.2013.10.021.

[16] Blanco N, Trias D, Pinho ST, Robinson P. Intralaminar fracture toughness characterisation of woven composite laminates. Part II: Experimental characterisation. Engineering Fracture Mechanics 2014;131:361-70. doi:10.1016/j.engfracmech.2014.08.011.

[17] Dalli D, Catalanotti G, Varandas LF, Falzon BG, Foster S. Mode I intralaminar fracture toughness of 2D woven carbon fibre reinforced composites: A comparison of stable and unstable crack propagation techniques. $\quad$ Engineering $\quad$ Fracture $\quad$ Mechanics 2019;214:427-48. doi:10.1016/j.engfracmech.2019.04.003.

[18] Moran PM, Liu XH, Shih CF. Kink band formation and band broadening in fiber composites under compressive loading. Acta Metallurgica et Materialia 1995;43:2943-58. doi:10.1016/09567151(95)00001-C.

[19] Catalanotti G, Xavier J, Camanho PP. Measurement of the compressive crack resistance curve of composites using the size effect law. Composites Part A: Applied Science and Manufacturing 2014;56:300-7. doi:10.1016/j.compositesa.2013.10.017.

[20] Bažant ZP, Kim J-JH, Daniel IM, Becq-Giraudon E, Zi G. Size Effect on Compression Strength of Fiber Composites Failing by Kink Band Propagation. International Journal of Fracture 1999;95:103-41. doi:10.1023/A:1018640015465.

[21] Pinho ST, Robinson P, Iannucci L. Fracture toughness of the tensile and compressive fibre failure modes in laminated composites 2006. doi:10.1016/j.compscitech.2005.12.023.

[22] Catalanotti G, Camanho PP, Xavier J, Dávila CG, Marques AT. Measurement of resistance curves in the longitudinal failure of composites using digital image correlation. Composites Science and Technology 2010;70:1986-93. doi:10.1016/j.compscitech.2010.07.022.

[23] Lisle T, Pastor M-L, Bouvet C, Margueres P. Damage of woven composite under translaminar cracking tests using infrared thermography. Composite Structures 2017;161:275-86. doi:10.1016/j.compstruct.2016.11.030. 
[24] Bažant ZP, Planas J. Fracture and Size Effect in Concrete and other Quasibrittle Materials. CRC Press LCC, ISBN 0-8493-8284-Xº 1998:616. doi:084938284x.

[25] Bažant ZP. Size Effect in Blunt Fracture: Concrete, Rock, Metal. Journal of Engineering Mechanics 1984;110:518-35. doi:10.1061/(asce)0733-9399(1984)110:4(518).

[26] Bažant ZP, Daniel IM, Zhengzhi L. Size Effect and Fracture Characteristics of Composite Laminates. Journal of Engineering Materials and Technology 1996;118:317-24.

[27] Salviato M, Kirane K, Esna Ashari S, Bažant ZP, Cusatis G. Experimental and numerical investigation of intra-laminar energy dissipation and size effect in two-dimensional textile composites. Composites Science and Technology 2016;135:67-75. doi:10.1016/j.compscitech.2016.08.021.

[28] Catalanotti G, Xavier J. Measurement of the mode II intralaminar fracture toughness and R-curve of polymer composites using a modified Iosipescu specimen and the size effect law. Engineering Fracture Mechanics 2015;138:202-14. doi:10.1016/j.engfracmech.2015.03.005.

[29] Zhuang F, Chen P, Arteiro A, Camanho PP. Mesoscale modelling of damage in half-hole pin bearing composite laminate specimens. Composite Structures 2019;214:191-213. doi:10.1016/j.compstruct.2019.01.062.

[30] Suo Z, Bao G, Fan B, Wang TC. Orthotropy rescaling and implications for fracture in composites. International Journal of Solids and Structures 1991;28:235-48. doi:10.1016/0020-7683(91)90208-W.

[31] ABAQUS Version 2017 Documentation. Dassault Systèmes 2017.

[32] Kuraishi A, Tsai SW, Liu KKS. A progressive quadratic failure criterion, part B. Failure Criteria in Fibre-Reinforced-Polymer Composites 2004;62:903-21. doi:10.1016/B978-008044475-8/50031-7.

[33] Hooper E, Bonitati A, Man M, Tanoto V, Lian E. TCAC 12k HTS40 SFP OSI / TC250 42 \% Fabric Prepreg Material Property Data Report. 2016.

[34] Hooper E, Tanoto V, Lovingfoss R, Lian E. Solvay Cytec Cycom EP 2202 T650 3K-PW Fabric 38\%RC Qualification Material Property Data Report. 2017.

[35] Hooper E, Man M, Lovingfoss R, Ng Y, Lian E. Cytec Cycom 5320-1 T650 3K-PW Fabric Qualification Material Property Data Report. 2015.

[36] Hooper E, Marlett K, Ng Y, Tomblin J. Hexcel 8552S AS4 Plain Weave Fabric Prepeg 193 gsm \& 38\% RC Qualification Material Property Data Report. 2011.

[37] Gurit. SE 84LV Low Temperature Cure Epoxy Prepreg- General Datasheet. 2017.

[38] Kuhn P, Catalanotti G, Xavier J, Camanho PP, Koerber H. Fracture toughness and crack resistance curves for fiber compressive failure mode in polymer composites under high rate loading. Composite Structures 2017;182:1-45. doi:10.1016/j.compstruct.2017.09.040.

[39] De Carvalho N V., Pinho ST, Robinson P. An experimental study of failure initiation and propagation 
in 2D woven composites under compression. Composites Science and Technology 2011;71:1316-25. doi:10.1016/j.compscitech.2011.04.019.

[40] Varandas LF, Catalanotti G, Melro AR, Falzon BG. On the importance of nesting considerations and accurate computational damage modelling of 2D woven composite materials. Computational Materials Science 2020;172:109323. doi:10.1016/j.commatsci.2019.109323.

[41] Melro AR, Camanho PP, Andrade Pires FM, Pinho ST. Numerical simulation of the non-linear deformation of 5-harness satin weaves. Computational Materials Science 2012;61:116-26. doi:10.1016/j.commatsci.2012.04.010.

[42] Faggiani A, Falzon BG. Predicting low-velocity impact damage on a stiffened composite panel. Composites Part A: Applied Science and Manufacturing 2010;41:737-49. doi:10.1016/j.compositesa.2010.02.005.

[43] Tan W, Falzon BG, Price M. Predicting the crushing behaviour of composite material using high-fidelity finite element modelling. International Journal of Crashworthiness 2015;20:60-77. doi:10.1080/13588265.2014.972122.

[44] Tan W, Falzon BG. Modelling the crush behaviour of thermoplastic composites. Composites Science and Technology 2016;134:57-71. doi:10.1016/j.compscitech.2016.07.015.

[45] Puck A, Schürmann H. Failure analysis of FRP laminates by means of physically based phenomenological models. Composites Science and Technology 2002;62:1633-62. doi:10.1016/S02663538(96)00140-6.

[46] Catalanotti G, Camanho PP, Marques AT. Three-dimensional failure criteria for fiber-reinforced laminates. Composite Structures 2013;95:63-79. doi:10.1016/j.compstruct.2012.07.016.

[47] Falzon BG, Liu H, Tan W. Comment on "A tensorial based progressive damage model for fibre reinforced polymers." Composite Structures 2017;176:877-82. doi:10.1016/j.compstruct.2017.06.011.

[48] Melro AR, Camanho PP, Andrade Pires FM, Pinho ST. Micromechanical analysis of polymer composites reinforced by unidirectional fibres: Part I-Constitutive modelling. International Journal of Solids and Structures 2013;50:1897-905. doi:10.1016/j.ijsolstr.2013.02.009.

[49] Tschoegl NW. Failure surfaces in principal stress space. Journal of Polymer Science Part C Polymer Symposia 1971;32:239-67.

[50] Bažant ZP, Oh B. Crack band theory for fracture of concrete. Materials and Structures 1983;16:155-77.

[51] Melro AR, Camanho PP, Andrade Pires FM, Pinho ST. Micromechanical analysis of polymer composites reinforced by unidirectional fibres: Part II-Micromechanical analyses. International Journal of Solids and Structures 2013;50:1906-15. doi:10.1016/j.ijsolstr.2013.02.007. 